Florida International University FIU Digital Commons

\title{
Pesticides and Pollination of Imperiled Plants of the Lower Florida Keys
}

Brittany M. Harris

Florida International University, bharr063@fiu.edu

DOI: $10.25148 /$ etd.FIDC000783

Follow this and additional works at: https://digitalcommons.fiu.edu/etd

Part of the Botany Commons, Entomology Commons, Environmental Health Commons, and the Terrestrial and Aquatic Ecology Commons

\section{Recommended Citation}

Harris, Brittany M., "Pesticides and Pollination of Imperiled Plants of the Lower Florida Keys" (2016). FIU Electronic Theses and Dissertations. 2548.

https://digitalcommons.fiu.edu/etd/2548 
FLORIDA INTERNATIONAL UNIVERSITY

Miami, Florida

\section{PESTICIDES AND POLLINATION OF IMPERILED PLANTS OF THE LOWER FLORIDA KEYS}

A thesis submitted in partial fulfillment of the requirements for the degree of MASTER OF SCIENCE

in

ENVIRONMENTAL STUDIES

by

Brittany Marie Harris

2016 
To: Dean Michael R. Heithaus

College of Arts, Sciences, and Education

This thesis, written by Brittany Marie Harris, and entitled Pesticides and Pollination of Imperiled Plants of the Lower Florida Keys, having been approved in respect to style and intellectual content, is referred to you for judgment.

We have read this thesis and recommend that it be approved.

Michael Ross

Joel Heinen

Suzanne Koptur, Major Professor

Date of Defense: July 06, 2016

The thesis of Brittany Marie Harris is approved.

Dean Michael R. Heithaus

College of Arts, Sciences, and Education

Andrés G. Gil

Vice President for Research and Economic Development and Dean of the University Graduate School

Florida International University, 2016 
C Copyright 2016 by Brittany Harris

All rights reserved. 


\section{ACKNOWLEDGMENTS}

I would like to thank my major advisor, Dr. Suzanne Koptur, for her mentorship and providing me with the opportunity to conduct ecological research in her lab. I also wish to thank the members of my committee, Dr. Michael Ross, Dr. Joel Heinen, and Dr. Jay for their continued support and advice. I would like to give a special thanks to the Agroecology Department and USDA-NIFA for funding support and the opportunity to participate in community outreach and science education projects, to the Garden Club of America and Pollinator Partnership for field and research funding through the 2015 Centennial Pollinator Fellowship, to the Kelly Foundation for the Tropical Botany Scholarship, and to Phillip Hughes, Adam Emerick, and Chris Eggleston at the US Fish and Wildlife Service for housing and technical support during my field research. Last, to all of my friends and my lab-mates in the Koptur Lab and Agroecology Lab: Tim Perez, Ian Jones, Kristie Wendelberger, Jaeson Clayborn, Nick Palermo, Ariel Freidenreich, Cleopatra Pimienta, Andrea Salas, Adel Peña, Christina Brown and Stephany AlvarezVentura for their valued input and personal support throughout the process of this thesis. 


\section{ABSTRACT OF THE THESIS \\ PESTICIDES AND POLLINATION OF IMPERILED \\ PLANTS OF THE LOWER FLORIDA KEYS}

by

Brittany Marie Harris

Florida International University, 2016

Miami, Florida

Professor Suzanne Koptur, Major Professor

Degraded pollinator habitat may have far-reaching consequences for recovery of imperiled flowering plant populations. Studies indicate that broad-spectrum insecticides used in mosquito abatement are detrimental to non-target invertebrates, including pollinators. A decline in efficient pollinators can reduce plant fitness by decreasing reproductive output and constraining genetic diversity, a challenge for rare plants.

In 2015, I monitored flower visitation and fruit set of three imperiled plant species throughout protected areas on three islands in The Lower Florida Keys. These islands consist of conservation land fragmented by intermittently dispersed residential neighborhoods that seasonally spray insecticides for mosquito control. Flowers open at treatment sites had decreased flower visitor activity following insecticide applications, but only species that require invertebrate agents for pollen transfer had significantly reduced fruit set. Implications of mosquito insecticides near conservation lands may pose immediate threats to invertebrate pollinators and flowering plants that require pollinators for reproduction, although long-term threats to genetic diversity are unknown for automatic self-pollinating species. 


\section{CONTENTS}

\section{CHAPTER}

PAGE

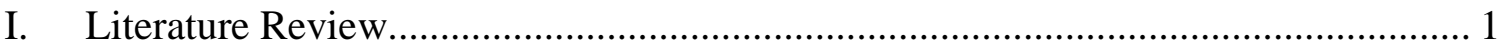

History of Mosquito Control in Florida ……………….......................................... 1

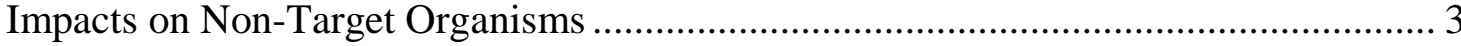

Indirect Effects on Community Function.............................................................. 7

Implications of Indirect Effects for Conservation ...................................................... 9

Drift into Non-Target Areas ............................................................................. 10

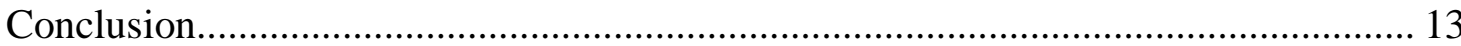

II. Pesticides and Pollination of Imperiled Plants of the Lower Florida Keys .............. 17

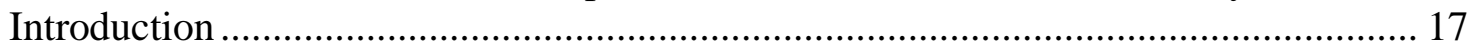

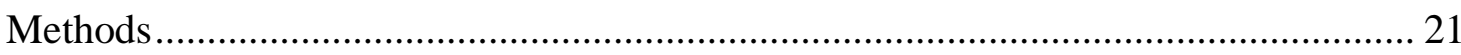

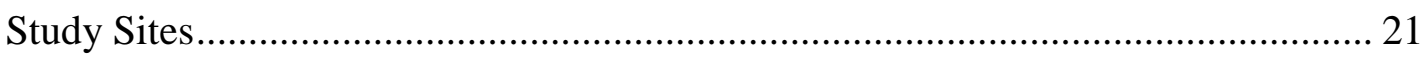

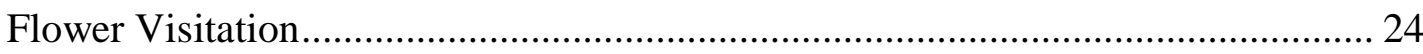

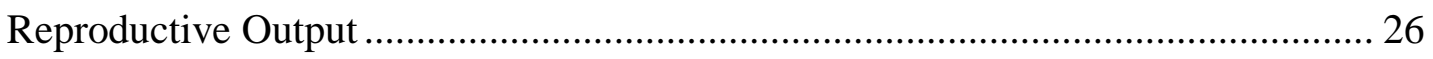

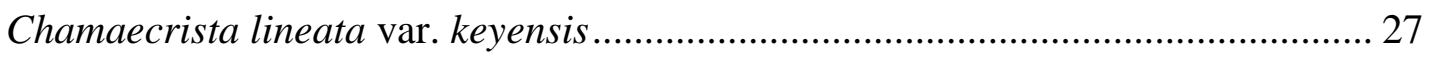

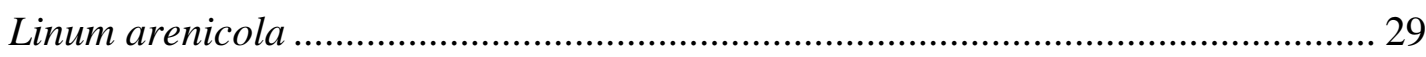

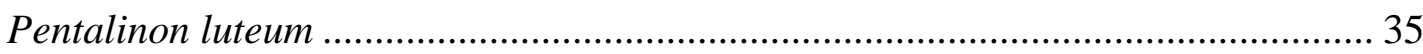

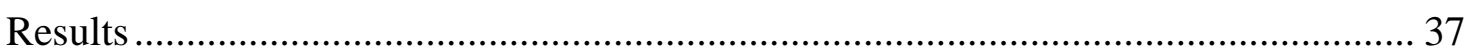

Chamaecrista lineata var. keyensis................................................................... 37

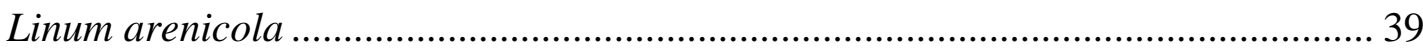

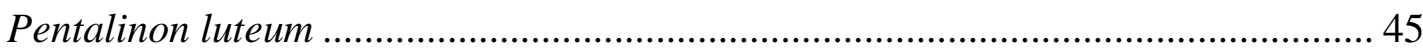

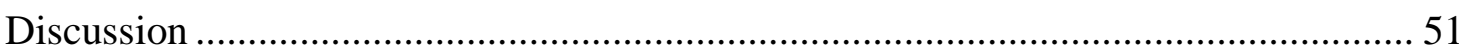

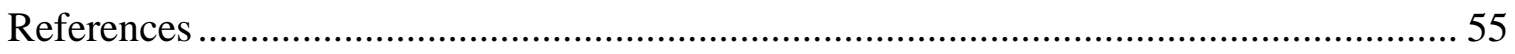

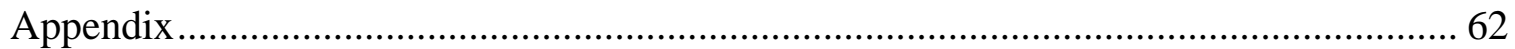




\section{LIST OF TABLES}

TABLE

PAGE

1. The Before After Control Impact (BACI) design for investigating direct and indirect effects of mosquito insecticide on Linum arenicola. Summary table lists groups and time intervals that will be analyzed to isolate mosquito spray as the variable responsible for differences in flower visitation and fruit set

2. Summary of Flower Visitation Rates to Linum arenicola and total observation times for control sites at Big Pine Key and the treatment site on Lower Sugarloaf after multiple spray missions during mosquito spray season (July - August 2015) and before the start of mosquito spray season (late March - early May 2016)

3. Summary of flower visitation rates to Pentalinon luteum and observation times for control sites at Big Pine, the treatment site on Lower Sugarloaf after multiple spray missions during mosquito spray season (July - August 2015), and flower visitation rates on No Name Key the day before and the day after the one insecticide spray mission in 2015. 


\section{LIST OF FIGURES}

FIGURE

PAGE

1. Study locations on No Name Key, Big Pine Key, and Lower Sugarloaf Key in the Lower Florida Keys. Red shading is the remaining pine rockland habit in the Keys, and green is rockland hammock habitat

2. Chamaecrista lineata var. keyensis individuals used in the present study on Big Pine Key. Only Whispering Pines Subdivision was sprayed in 2015. Flower visitation rates and proportion fruit set was simultaneously measured for individuals at Control Sites and at the area labeled Critical Habitat $>350 \mathrm{~m}$ from spray route) following mosquito insecticide applications at Whispering Pine

3. Big Pine Key. Linum arenicola and Pentalinon luteum control sites within National Key Deer Refuge on Big Pine Key. Sites for both species occurred road-side with one remote reference site for each species.

4. Figure 4. Linum arenicola and Pentalinon luteum populations along mosquito adulticide ULV truck route on Lower Sugarloaf Key. The route for aerial missions covers the whole island (not shown)

5. Pentalinon luteum population occurring parallel to the mosquito adulticide truck route on No Name Key within National Key Deer Refuge boundary.

6. Pollinator Visitation Rates to Linum arenicola populations at control sites (Big Pine Key) and the treatment site (Lower Sugarloaf Key) after multiple seasonal spray missions (JulyAugust 2015) and before the start of mosquito spray season (late March - early May 2016). Means with different letters are significantly different (Mann-Whitney $U, p<.05$ ).

7. Manipulation experiments on Linum arenicola flowers comparing fruit set with 'exposed' open flowers and 'bagged' open flowers to prevent flower visitation. Means with different letters are significantly different (Chi-square, $\mathrm{p}<.01$ )

8. Mean Proportion Fruit Set for Linum arenicola populations at control sites (Big Pine Key) and the treatment site (Lower Sugarloaf Key) after multiple seasonal spray missions (JulyAugust 2015) and before the start of mosquito spray season (late March - early May 2016). Means with different letters are significantly different (Chi-square, $p<.05)$. 
9. Pollinator visitation rates to Pentalinon luteum populations at control sites (Big Pine Key) and the treatment site (Lower Sugarloaf Key) after multiple seasonal spray missions (July - August 2015) and before the start of mosquito spray season (late March - early May 2016). Means with different letters are significantly different (Mann-Whitney U, $\mathrm{p}<.05)$

10. Proportion fruit set for Pentalinon luteum at Big Pine Key control sites and Lower Sugarloaf Key treatments sites following insecticide spray activity and fruit set at treatment site over 14 days after spray activity. Means with different letters are significantly different $($ Chi-square, $\mathrm{p}<.05)$

11. Visitation rates to open flowers of Pentalinon luteum on No Name Key, the day before, the day after, and 10 weeks after a mosquito insecticide application on this site. Only one application occurred on No Name Key for the spray season. Means with different letters are significantly different $($ Chi-square, $\mathrm{p}<.05)$

12. Proportion fruit set of open flowers of Pentalinon luteum on No Name Key, the day before and the day after a mosquito insecticide application on this site. Only one application occurred on No Name Key for the spray season. Means with different letters are significantly different (Chi-square, $\mathrm{p}<.05)$ 


\section{Literature Review}

\section{History of Mosquito Control in Florida}

South Florida is a tourist destination renowned for its warm weather, sandy beaches, and diversity of subtropical flora and fauna. It was not always a desirable place to live or visit, however, and until the early $20^{\text {th }}$ century was sparsely inhabited (Patterson 2004). According to writings from early European explorers, Florida was "flat, watery, and populated with an exceptionally large number of mosquitos" (Patterson 2004), as Florida's subtropical coastal wetlands are ideal breeding grounds for mosquitos (Dale \& Knight 2008). Aggressive nuisance mosquitos not only deterred early explorers from settling in Florida, but also transmitted deadly disease to many of those who did (Connelly \& Carlson 2009).

Since the discovery of the mosquito's role as a disease vector, humans have struggled to eradicate mosquitos with continuously evolving techniques. Yellow fever and malaria epidemics through the 1880 s provoked anti-mosquito sentiment and the earliest efforts for mosquito abatement. Projects targeted mosquito breeding sites by draining wetlands and stocking drainage ditches with predatory mosquito fish throughout much of Florida; such ditches are still part of the topography on Big Pine Key today. These projects were permanent and effective at controlling the spread of yellow fever and malaria but were expensive, labor intensive, and therefore, short-lived (Patterson 2004; Connelly \& Carlson 2009). Eradication efforts were considerably renewed after WWII, when chemical insecticides became widely available. Insecticides, like dichlorodiphenyl-trichloroethane (DDT), were inexpensive and highly effective at rapid 
knockdown of nuisance and disease vector mosquitos (Patterson 2004; Connelly \& Carlson 2009). Throughout Florida, nearly all existing mosquito control districts created spray programs incorporating these revolutionary insecticides (Connelly \& Carlson 2009), use of which was extensive and unregulated.

Although insecticides were celebrated as a complete solution to mosquito eradication, scientists recognized the need for alternative methods (Connelly \& Carlson 2009). Risk of adverse effects of indiscriminate spraying were not initially considered, and within several years, widespread and unregulated application of DDT had documented inadvertent effects on non-target organisms. Rachel Carson brought many of these concerns to the public forefront in her book Silent Spring (Carson 1962). She and other scientists questioned indiscriminate use of insecticides and suggested adverse effects to non-target organisms, pest resistance to chemicals, bioaccumulation in individuals and the environment, and potential for chemicals to drift into unintended areas (Patterson 2004). Pioneering studies reported that aerial DDT applications decreased fecundity and resulted in population declines in eagles, peregrine falcons, and other predatory birds (Connell 1999). Banning the use of DDT for mosquito control was critical to recovery of these bird populations (USFWS 2010a). Those early studies raised public awareness of potential risks towards irresponsible insecticide use by the administering agencies (Patterson 2004). 


\section{Impacts on Non-Target Organisms}

Nearly sixty years of empirical evidence suggest that broad-spectrum insecticides used in mosquito control are detrimental to non-target organisms, particularly invertebrates. Non-target impact studies have in recent years encouraged regulation and limitations on insecticide use by some mosquito control districts (USFWS 2014); however, insecticides are regularly administered to control high abundances of adult nuisance mosquitos in some regions. Florida mosquito control districts primarily use pyrethroids (Permethrin) in ground application, and DiBrom® (Naled), an organophosphate, for aerial missions (Connelly \& Carlson 2009). They are dispersed via an ultra-low volume (ULV) system that emits fine mist particles of undiluted insecticide for expansive coverage of flying insects (Zhong et al. 2010). These broad-spectrum adulticides are both neurotoxins, intended to reduce or eliminate pestiferous insects; neither is taxon specific (USEPA 2006). Naled and Permethrin are approved for use in public health and agriculture to control a variety of crop pests (Coats et al. 1989; USEPA 2002), and they are marketed to control beetles, mosquitos and other Dipterans, Hemipterans, and Orthopterans of economic importance (Bradbury \& Coats 1989). Naled, used in aerial missions by mosquito control districts throughout Florida, is no longer available to homeowners and professionals for use in or around neighborhoods (USEPA 2002), and has been banned from use by countries in the European Union (European Commission 2012) due to potential health effects to humans to pets.

Invertebrates vary in response to insecticide exposure. Broad-spectrum adulticides are effective on an array of invertebrates, but lethality is greatest for small organisms with a high surface to volume ratio (Johansen 1977; Tomlin 2000; Wisk et al. 2014). 
Although invertebrates differ in response to insecticides, honeybees (Apis mellifera), are currently the only terrestrial invertebrate assessed in non-target toxicity studies in the EPA registration process for Naled and Permethrin (USEPA 2002; USEPA 2006); other studies suggest that multiple species of butterflies and wild bees may be more appropriate test subjects (Tepedino et al. 1996; Hoang et al. 2011). In addition to EPA evaluation, other non-target impact studies generally focus on a very small subset of economically important and well-studied species, namely honeybees and Daphnia sp. (Breidenbaugh \& Szalay 2010; Brittain 2010; Hoang et al. 2011; Antwi \& Reddy 2015). Few studies quantify differences in lethality between invertebrate groups, such as pollinator assemblages (Johansen 1972; Arena \& Sgolastra 2014). Considering variability in response among taxa and functional groups, singular focal species may not be good general representatives of non-target organisms collectively.

Neighboring invertebrates receiving the same insecticide exposure, organisms with similar functional traits, and even closely related organisms are frequently shown to respond differently to insecticides. Pyrethroids are 'highly toxic' to non-target aquatic invertebrates (e.g.,, Daphnia sp., Ephemeroptera larvae) at low concentrations (Bradbury \& Coats 1989), while neighboring mollusks exposed to the same concentrations may experience no negative effects (Coats et al. 1989). Functionally similar groups (e.g., pollinator guilds) and taxonomically similar groups (e.g., bees) may also be affected differently. In a breeding system study of a bee-pollinated plant in the Lower Florida Keys, Liu and Koptur (2003) noted reduced flower visits of Melissodes spp. and Xylocopa micans, but not of Megachile spp. following an aerial mosquito insecticide application. Extensive studies suggest that insecticides like permethrin and 
Naled are lethal to honey bees (Apis mellifera) (Fischer et al. 2014; USEPA 2002;

USEPA 2006), while other members of Apoidea may experience sub-lethal effects at similar doses (Vaughan et al. 2014). In addition, butterflies from the family Lycaenidae experience mortality more readily than those of Hesperiidae (Bargar 2012).

Life histories may provide some insight into species-specific sensitivity at various spatial scales. Activity of immature stages, feeding behavior, seasonality, and timing of spraying can all affect insecticide exposure and sensitivity. Nocturnal invertebrates are potentially more vulnerable to insecticide exposure during evening truck applications than morning aerial applications, and vice versa for diurnal feeders and foragers (Longley \& Sotherton 1997; Breidenbaugh \& Szalay 2010). In addition, phytophagous beetles experience greater lethality than predaceous beetles (Coats et al. 1979), indicating that diet may be an important factor for toxicity among organisms. Nesting and burrowing in enclosed areas (e.g., tree and stem holes, underground, or within flower buds or leaves) could also provide some protection from ambient insecticide spray, while above ground nesters may be more vulnerable to airborne insecticide particles (Salvato 2001; Wisk et al. 2014). Varying responses of functionally similar groups to equal insecticide concentrations may depend upon the spatial scale of observations chosen for a given study: groups that appear to vary in sensitivity at one scale of resolution may exhibit similar responses at another scale (Brittain 2010). In a landscape analysis of agricultural insecticides and pollinator species diversity, multiple insecticide applications at a small spatial scale caused significant declines in wild bee species richness but not butterfly species richness, while both groups experienced declines at the regional scale (Brittain 2010). 
Sub-lethal effects and population recovery of non-target organisms from insecticide applications also have an important temporal component that may vary throughout the mosquito control season. Sub-lethal toxicity may prolong certain death or decrease fecundity in some organisms by reducing foraging or diminishing feeding, thus having a marked effect on reduction in growth, reproduction, and behavioral changes (Tan 1981b; Coats et al. 1989; Devillers 2002). Bioaccumulation may also have an effect on non-target species, in which compound exposure to insecticides may increase lethality. Brittain et al. (2010) found that native bee species richness was not affected after one insecticide application in an agricultural field in Italy, but after two to three applications, bee richness markedly decreased. Zhong et al. (2009) found a similar correlation between butterfly larval mortality and repeated insecticide exposure applications. Larval mortality was lowest after one aerial ULV application of Naled for mosquito control, and highest mortality after the sixth and final treatment. Even if insecticides are applied at sub-lethal doses, multiple rounds of exposure by the end of the season could have cumulative detrimental effects (Brittain 2010; Zhong et al. 2010). While frequent applications may increase toxicity, studies suggest that extended time between insecticide applications may assist population recovery for non-target organisms. Mulla et al. (1992) found 50-100\% lethality in non-target aquatic invertebrates immediately following a pyrethroid application; populations of Odonata, Hemiptera, and Coleoptera recovered within 2 weeks, while Ephemeroptera populations did not. Mosquito insecticide spay frequency can have marked effects on bioaccumulation and may, therefore, be an important factor for population impact studies on non-target organisms. 
Field and lab toxicity studies suggest that pyrethroids and organophosphates adversely affect an array of non-target terrestrial invertebrates. Impact studies suggest that mosquito adulticides have direct adverse effects to butterflies (Bargar 2012; Carroll \& Loye 2006; Eliazar \& Emmel 1991; Hennessey \& Habeck 1991; Salvato 2001; Zhong et al. 2010), parasitoids (Coats et al. 1979), and native and non-native bee pollinators (Kevan \& Plowright 1989; Kevan et al. 1997; Liu \& Koptur 2003; Wisk et al. 2014). In addition, non-target impact studies from agricultural applications of the same broadspectrum insecticides are numerous (Schleier \& Peterson 2014; Fischer \& Moriarty 2014); however, these studies should be extrapolated with some degree of caution, as concentrations, application method, and frequency vary for uses between agriculture and mosquito control (USEPA 2006; Schleier et al. 2012). Future research is needed to understand the factors that affect responses of broad-spectrum adulticides to non-target invertebrates, including the role of life history traits of various species and spatial and temporal responses, factors that are not well understood, and for which extensive field studies and knowledge of the species of concern could provide much valuable information.

\section{Indirect Effects on Community Function}

While evidence suggests that mosquito insecticides have a direct effect on nontarget invertebrates, studies on indirect effects (e.g., on trophic interactions and mutualisms) are less frequent in the literature (Brittain et al. 2010). In a mesocosm study, broad-spectrum mosquito insecticides reduced zooplankton population causing reduced 
fitness of one of two amphibian species in a trophic cascade across four trophic levels (Relyea \& Diecks 2008). These types of small-scale closed system studies can be effective at isolating interaction mechanisms, but are not a realistic replacement for field monitoring (Shaw \& Kennedy 1996). Indirect effects on invertebrate interactions can be confounded by external variables, such as alternative food resources, refuge habitat, or temporal variation in life histories (Niemi et al. 1999). Long-term studies on a large spatial scale may be necessary for indirect effects of insecticide exposure to be discernable (Niemi et al. 1999; Brittain 2010).

Ambient mosquito insecticide spray may affect community processes by disrupting interactions between plants and insects (e.g., pollination). Plants that depend on pollinators are vulnerable to changes in pollinator presence (Kearns et al. 1998; Dunn et al. 2009), which may bring adverse effects to reproductive fitness (i.e., fruit and seed set) (Kevan 1975; Johansen 1977; Tepedino 2000; Brittain et al. 2010). By some estimates, over $90 \%$ of all angiosperms benefit from or depend on insect pollinators for reproductive fitness (Buchmann \& Nabhan 1997), including many rare plants and economically valuable agricultural crops, such as blueberries, almonds, cucurbits, mangoes, and avocados (Tepedino 1979; Kevan et al. 1990). Studies in agricultural systems suggest that broad-spectrum insecticides indirectly affect plant reproduction by reducing pollinator abundance (Johansen 1977; Kevan \& Plowright 1989; Brittain et al. 2010). In an agricultural field in Italy, seed set, seeds per plant, and flower visitor abundance of a horticultural Petunia were significantly reduced after two applications of fenitrothion, an organophosphate, though pollinator species richness increased (Brittain et al. 2010). In another textbook example, a significant seasonal decrease in blueberry crop 
production was measured during aerial insecticide applications to a nearby forest (Kevan \& Plowright 1989); blueberries require pollinators for fruit set, therefore decreased native pollinator abundance in the field reduced lowbush blueberry production.

Although empirical evidence suggests that broad-spectrum insecticide applications are detrimental to pollinators, many of these studies are in controlled lab settings and fail to consider sub-lethal effects to behavior (e.g. reduced foraging for floral resources) and consequential effects to reproduction in flowering plants (Allen-Wardell et al. 1998). Liu and Koptur (2003) observed a noticeable decrease in flower visitors to Chamaecrista lineata var. keyensis in the Lower Florida Keys following an application of mosquito insecticides (Liu \& Koptur 2003). Further research is needed to understand indirect effects of mosquito insecticides on community function, including pollination systems, food webs, trophic cascades, and other invertebrate symbiotic interactions.

\section{Implications of Indirect Effects for Conservation}

Many rare plant species are dependent on invertebrate flower visitors for fruit and seed production. Not only is sexual reproduction in rare plants essential to maintaining genetic diversity necessary for long-term persistence (Bond 1994), but frequently rare species have advanced pollination systems in which reproduction does not occur in the absence of flower visitors (Tepedino 2000). Tepedino (2000) found that 24 of 26 rare plants in the Southwest US required invertebrates as a pollinating agent for fruit set. Pollinators encourage gene flow by moving gametes between plants of the same species, and at the same time, can be agents of selection on plant floral morphology and even speciation (Tepedino 1979; Kearns et al. 1998; Johnson \& Steiner 2000). 
Hennessey and Habeck (1991) investigated effects of ambient mosquito insecticide on pollinator visitation and fruit set of the federally endangered Key Tree Cactus (Pilosocereus robinnii) in the Lower Florida Keys. However, they found no significant difference in fruit set rates between treated and untreated sites, as this species is highly self-compatible and readily produced fruit in 'bagged' flowers excluded from pollinators. Differences in flower visitation rates could not be calculated because visitors were not present during observation periods for all $P$. robinnii individuals, including unsprayed sites. The authors suggest that efficient pollinators may no longer be present throughout $P$. robinnii's range (Hennessey \& Habeck 1991). Although the plant species has declined by 80\% between 1994 and 2007 (USFWS 2010b), autogamy allows the species to persist, but may prevent new individuals from adapting to a changing environment, such as salt-water intrusion, herbivory, or disease (Tilman 1994; Proctor $e t$ al. 1996; Bond 1994).

\section{Drift into Non-Target Areas}

Insecticide drift in non-target areas is a potential challenge for managing vulnerable species at the wild-land urban interface. Drift from mosquito insecticide applications can have adverse effects, including lethality, to non-target organisms (Zhong et al. 2010). In a drift investigation study, residues of two mosquito control insecticides, fenthion (pyrethroid) and Naled (organophosphate), were found deposited on cellulose pads in 'no spray zones' in protected areas throughout the Florida Keys (Hennessey et al. 1992). While fenthion residues applied by trucks were found at $50 \mathrm{~m}$ inside non-target areas, drift residues of Naled applied by aircraft ranged from $30 \mathrm{~m}$ up to $750 \mathrm{~m}$ into 'no 
spray' zones (Hennessey et al. 1992), including habitat of the endangered Bartram's scrub hairstreak and other rare invertebrate and flowering plant species (Hennessey and Habeck 1991). In another Florida Keys drift study, truck ULV applications of permethrin were deposited on filter papers in non-target area offshore in the Florida Keys Marine Sanctuary weeks after application (Pierce et al. 2005). Drift concentrations, distance, and persistence are inconsistent among studies and are likely influenced by a multitude of external factors (Schleier et al. 2012).

Application methods can affect insecticide dispersal and drift into non-target areas. In Florida, mosquito control districts primarily apply insecticides by aircraft to cover large populations of nuisance mosquitos over large areas, and trucks for smaller populations in neighborhoods. Both methods use Ultra-Low Volume systems that emit small, undiluted mists of insecticide particles that persist in the air column until volatilized or degraded. Suspended particles maximize the potential for contact with adult flying mosquitos, allowing for rapid knockdown of high mosquito abundances (Haile et al. 1982; Mount et al. 1996). With minimal wind during applications, the small particle size creates an even extensive coverage with faster degradation (i.e., lower persistence) and less concentrated drift than other methods like aerial thermal fog applications (Hennessey et al. 1992). However, various spray attachments are available for the ULV systems that emit a range of droplet sizes that can affect drift distance and concentrations, which results in inconsistencies between studies that investigate adverse effects to nontarget organisms (Dukes et al. 2004; Breidenbaugh et al. 2009). For example, in a study comparing two ULV nozzle attachments, insecticide drift was found on yard strings over $8000 \mathrm{~m}$ from flight path for both methods, with one attachment causing $17 \%$ fiddler crab 
mortality at 4,500m from spray source, and the other causing little to no fiddler crab mortality (Dukes et al. 2004).

Abiotic factors during the time of insecticide spray also affect drift distance and concentration, and should be an important consideration in mosquito abatement near sensitive habitat for rare species. Humidity, wind speed, wind direction, and atmospheric stability determine the rate and distribution of ground deposition and particles suspended in the air column (Schleier et al. 2012). Insecticide spray applied with the Ultra-Low Volume system drifts downwind, and concentrations decrease with distance from the source of spray (Pierce et al. 2005). High humidity, high temperature, and stable atmospheric conditions are positively correlated with rates of ground deposition (Schleier et al. 2012). Under stable atmospheric conditions with low wind speeds, drift is minimal and concentration near the source of spray is highest (Dukes et al. 2004). Accordingly, non-target invertebrates in flight near application routes are most vulnerable to insecticide exposure (Longley \& Sotherton 1997). The optimum conditions for insecticide efficacy for mosquitos that are least harmful to non-target organisms are unclear, but calm winds, stable atmospheric conditions, warm temperatures, and low humidity are optimal for predictable consistent application (Connelly \& Carlson 2009; USEPA 2002).

Field studies are scarce and inconsistent on insecticide persistence in the environment and exposure routes to non-target organisms. Toxicity studies on the persistence of both Naled and permethrin are frequently derived from degradation of particles in soil (URS Corporation 2004); however, the vast majority of ULV applied insecticides do not reach the soil surface. For truck ULV applications, $1 \%$ to $30 \%$ of 
insecticide particles reach the ground within $100 \mathrm{~m}$ of spray source, with an average of $10 \%$ ground deposition within 180m (Schleier et al. 2012); most particles remain suspended in the air column or as foliar residues until they degrade or volatilize. Pesticides that reach the soil surface degrade within half an hour (USEPA 1997), whereas surface residues (such as filter papers exposed in the open) have a half-life of 1.5 to 55 hours in full sunlight and 8 to nearly 100 hours in darkness (Hennessey et al. 1992; USEPA 1997; Tietze et al. 1996). Rapid breakdown in soil suggests that soil microbes likely facilitate insecticide degradation (USEPA 1997), and therefore, half-life on soil surface may not be a good indicator of environmental persistence. In addition, insecticide particles not volatilized must penetrate the canopy layer before reaching the soil surface, and interception by the canopy is dependent upon foliar density (URS Corporation 2004), which varies between sprayed areas. Permethrin residues can remain on vegetation for several days (Pierce et al. 2005; USEPA 2006). For broad-spectrum insecticides, deposition on vegetation, flowers, and fruit may increase routes of exposure for resting or foraging invertebrates through dermal contact, nesting materials, or ingestion (URS Corporation 2004; Wisk et al. 2014), although these routes are not well understood for non-target organisms and are likely dependent upon a number of temporal and spatial factors, as well as on the behavior of the organisms of interest.

\section{Conclusion}

Toxicity from broad-spectrum insecticides is variable among non-target organisms and not fully understood. Sub-lethal affects can acutely affect vital behavioral activity, such as feeding and reproduction; this may have an unapparent impact on mutualistic relationships and trophic interactions that are not generally considered in lab 
toxicity studies. Life history traits of individual species may be key to susceptibility to broad-spectrum insecticides. Although much research has been dedicated to understanding abiotic factors that influence insecticide dispersion and lethality in nontarget organisms, additional research is imperative to understand ensuing community level biotic interactions. Trophic interactions and mutualisms, such as pollination, are crucial for community function and are likely affected by invertebrate declines from broad-spectrum mosquito insecticides. However, community-level studies are rarely considered in broad-spectrum insecticide impact studies.

Aerial and truck ULV applied mosquito insecticides have also been shown to drift into non-target areas, such as protected areas. This can be problematic for species that depend on protected habitat for survival, such the Schaus Swallowtail Butterfly, the Miami Blue, or Bartram's Scrub Hairstreak, as well as rare plants that depend on pollinators for reproductive success. In addition, spatial and temporal conditions of insecticide spray may greatly affect impacts to non-target organisms, which may explain much of the variability in results for previous impact studies. Timing of the day insecticides are sprayed, spray frequency, time between sprays, nearby refuge habitat for invertebrates, and spray drift distance and concentration may affect the degree of exposure and toxicity to non-target organisms. One consistent result in the literature is that multiple insecticide applications in one season has the greatest effect on non-target invertebrate populations. Mosquito control districts should therefore be cautious in high frequency of spray applications by alternating abatement methods for management. Additionally, creating buffer zones of 'no spray' routes near sensitive conservation areas 
may alleviate negative direct and indirect consequences of broad-spectrum insecticides to non-target organisms.

With expanding urban development in South Florida, protected species in fragmented habitats are more exposed than ever to anthropogenic activity at the wild-land urban interface. Although direct impacts of insecticides on invertebrates have been well documented, there is an urgent need to understand indirect effects to flowering plants, both common and rare, that occur in protected areas and are susceptible to drift from broad spectrum insecticides. Several plant species within the National Key Deer Refuge (NKDR) in the Lower Florida Keys have currently been proposed for endangered status, yet potential consequences of insecticides on pollination of the species are unknown. An opportunity to contribute to a better understanding of this potential threat to the pollination system of these and other sensitive plant species presented itself when David Bender of the US Fish and Wildlife Service approached Dr. Suzanne Koptur, a pollination biologist and my major advisor, for prospective funding to undertake such a project; indirect effects of broad-spectrum insecticides are not always obvious and, consequently, are infrequently studied. Though funding for the proposal we developed was not secured through USFWS, the proposed objectives provided an excellent opportunity for a master's research project in pollination and plant conservation, a subject of much personal interest. My resulting thesis project received immense support from USFWS - NKDR staff, Garden Club of America and Pollinator Partnership, the USDANIFA, and the Kelly Foundation. My intent is for this study to provide a better understanding of the role pesticides have on pollinators and plant reproduction, so that 
conservation agencies may consider pollinator habitat and community processes in efforts to protect plants and wildlife in conservation areas. 


\section{Pesticides and Pollination of Imperiled Plants of the Lower Florida Keys}

\section{Introduction}

Degraded pollinator habitat may have far-reaching consequences for recovery of imperiled flowering plant populations at the wild-land urban interface. Global declines in invertebrate pollinators are linked to a suite of factors, including reduced habitat quality from broad-spectrum insecticide applications (Kevan \& Plowright 1995; Tepedino et al. 1996; Buchmann \& Nabhan 1997; Potts et al. 2010; Brittain 2010). Studies suggest that insecticides used in mosquito abatement are detrimental to non-target flying invertebrates, including pollinators (Kevan \& Plowright 1989; Eliazar \& Emmel 1991; Salvato 2001; Brittain 2010; Zhong et al. 2010; Bargar 2012). Declines in pollinator abundance and species richness have a significant impact on reproductive fitness of imperiled flowering plants (Allen-Wardell et al. 1998; Kearns et al. 1998; Tepedino 2000). Pollinator availability influences flower visitation rates and fruit set in animal pollinated plants (Kearns et al. 1998). A decline in effective flower visits often leads to pollen limitation in plants, resulting in reduced fruit set and seed set (Kearns et al. 1998). Despite the fact that $90 \%$ of flowering plants benefit from or rely upon insect pollinators for reproductive fitness (Buchmann \& Nabhan 1997), plant-pollinator interactions are rarely considered in conservation strategies for flowering plants (Tepedino et al. 1996; Buchmann \& Nabhan 1997; Kearns et al. 1998; Johnson \& Steiner 2000).

Rare plants and plants with specialized breeding systems are particularly vulnerable to decreased pollinator visitation. Pollinators enhance genetic diversity of flowering plants by assisting in sexual reproduction and outcrossing, thereby improving 
reproductive fitness, a goal for stabilizing rare populations (Kearns et al. 1998; Johnson \& Steiner 2000; Marcot \& Molina 2007). Many rare plants also have advanced pollination systems, which can make them dependent upon pollinators for reproduction (Tepedino 2000; Spira 2001). In addition, flowering plants with specialized pollinator relationships (e.g., monophilic and oligophilic plants) are more vulnerable to pollinator declines than plant species visited mostly by generalist pollinators (Allen-Wardell et al. 1998; Johnson \& Steiner 2000; Xiao et al. 2016).

Though most plants benefit from, or rely on pollinators for reproduction, flexibility in reproductive strategies for plants may mask ecological effects of decreased flower visitors from insecticide application. Automatic self-pollination is a common failsafe mechanism in short-lived herbaceous plants when efficient pollinators are sparse ((Bond 1994; Proctor et al. 1996). For rare plants, however, reliance on self-fertilization can constrain genetic diversity (Allen-Wardel et al. 1998). For example, deleterious alleles may surface that would have otherwise been masked by heterozygosity in offspring produced from two unrelated parent individuals (Charlesworth \& Charlesworth 1987). This mechanism may mask ecological instability, such that populations may be apparently viable but doomed in the long run, harboring an 'extinction debt' (Tilman 1994; Chen 2009; Johnson \& Steiner 2000). Understanding the reproductive strategies and pollinator dependency of rare plants could assist in management efforts to improve habitat quality for pollinators, thereby reducing threats to rare plant populations.

National Key Deer Refuge in the Lower Florida Keys contains a high diversity of flowering plants and invertebrate pollinators, including several federally listed species endemic to the Keys (Gann et al. 2007). Development of roads and neighborhoods 
throughout the Refuge have resulted in a matrix of fragmented wildland patches with an increased edge exposure to anthropogenic activity (Koptur 2006). Increasing urbanization and tourism around the Refuge has consequently increased the demand for mosquito abatement (Hennessey et al. 1992). The Florida Keys Mosquito Control District (FKMCD) applies mosquito insecticides between mid-spring and late fall in the Lower Florida Keys, throughout neighborhoods and roads adjacent to Refuge land. Insecticides can drift outside of target areas into adjacent wildland habitat that serve as a refuge for native biota (Hennessey et al. 1992; Pierce et al. 2005; Zhong et al. 2010; Bargar 2012). Drift can pose a potential challenge for managing vulnerable species at the wildland-urban interface. In a study in the Lower Keys to quantify drift distance into conservation land, aerial drift residues of Naled were found up to 750 meters within a 'no spray' zone, while ground pyrethroid residues from ULV application were found 50m outside of the target area (Hennessey et al. 1992). Reports of drift distance and persistence are inconsistent across studies, as these factors are influenced by abiotic factors and application methods; for example, one study found drift residues as far as 8000m from flight path (Dukes et al. 2004). These insecticides can be fatal to non-target invertebrates at the wildland-urban interface and potentially pose threats to ecological processes within wildland communities (Hennessey \& Habeck 1991; Liu \& Koptur 2003).

Extensive studies, particularly in the Florida Keys, suggest that broad-spectrum adulticides used in mosquito abatement negatively affect non-target invertebrates, including pollinators (Eliazar and Emmel 1991, Hennessey and Habeck 1991, Kevan et al. 1997, Salvato 2001, Carroll et al. 2006, Zhong et. al 2010, Bargar 2011, Hoang et al. 
2011). However, indirect effects to plant-pollinator interactions and reproductive fitness in pollinator dependent plants are not very well understood (Hennessey \& Habeck 1991; Brittain et al. 2010).

Effects on plant reproduction are dependent on both lethal and sub-lethal effects to potential pollinators and dependency of plants on flower visitors for fruit and seed production. Non-target organisms respond differently to insecticide exposure throughout the mosquito control season (Brittain 2010; Zhong et al. 2010). Sub-lethal effects and frequency of treatments may be important factors for consideration in impact studies and population recovery of non-target organisms. Sub-lethal exposure can decrease fecundity in some organisms by reducing feeding time or feeding cessation (i.e., decreased flower foraging) and having a marked effect on reduction in growth, reproduction, and behavioral changes (Coats et al. 1979; Tan 1981a). Behavioral changes in foraging could have secondary adverse effects for plants that rely on efficient flower visitors for pollination; however, this is rarely investigated (Allen-Wardell et al. 1998). Frequent insecticide application may also lead to bioaccumulation in non-target species, in which compound exposure to insecticides throughout the season may increase lethality (Brittain 2010; Zhong et al. 2010). Furthermore, reducing the frequency of insecticide applications (>14 days between applications) can have a positive effect on population recovery for some common non-target organisms, although recovery lengths may vary for species (Mulla et al. 1982).

In the present study, I investigate potential direct and indirect effects of ambient mosquito insecticide spray on flower visitation and reproductive success of two imperiled and one common plant species in protected areas in the Lower Florida Keys. I consider if 
extended time between spray applications (> 14 days between applications) has a less negative effect on proportion fruit set. In addition, I consider effects of multiple seasonal insecticide applications on visitation to flowers and proportion fruit set, and if populations exposed to one seasonal insecticide spray exhibit similar results. My hypothesis is that flowers open following an insecticide application at sites that are frequently treated will have lower visitation rates, and therefore, lower fruit set than synchronously open flowers in unsprayed areas. I also postulate, from evidence in previous studies, that areas exposed to only one insecticide treatment will have little effect on flower visitation and fruit set. Provided that adverse effects to pollinators are not irreversible in areas with frequent seasonal spray activity (i.e., recovery of pollinator populations occurs between mosquito spray seasons), flowers open before the mosquito spray season at treated areas should have similar flower visitation rates and fruit set to control sites at the same time.

\section{Methods}

\section{Study Sites}

The Lower Florida Keys (Lower Keys) is the southernmost portion of the subtropical island chain in extreme South Florida. It consists of submerged and exposed marine oolitic limestone substrate, in which vegetative communities are shaped by smallscale elevational gradients (Ross et al. 1992). Upland outcroppings of limestone throughout the Lower Keys create unique pine rockland and rockland hammock habitat (Ross \& Ruiz 1996) for a large diversity of flora and fauna, including many narrowly endemic species (Gann et al. 2007). Pine Rockland historically occurred along the South 
Florida Miami Rock Ridge through a portion of the Lower Florida Keys and the Bahamas, however, this habitat has been under continuous decline with pressures from urban development and habitat degradation from fire exclusion, invasive species, and sea level rise (USFWS 2015). Estimates suggest that only $2 \%$ of the original pinelands outside of the Everglades remain intact in South Florida (Koptur 2006). The IUCN globally endangered habitat is fire dependent and features an open canopy sparsely dominated by South Florida Slash Pine (Pinus elliottii var. densa), several species of understory palms and shrubs, and a species rich herbaceous layer (USFWS 1999, Saha et al. 2011). Federal and State conservation areas cover large tracts of land throughout the Lower Keys. Much of the remaining pine rockland outside of the Florida mainland occurs within National Key Deer Refuge (NKDR) in the Lower Keys. NKDR pine rockland is habitat for several federally endangered and threatened flowering plant and butterfly species.

I investigate effects of mosquito insecticide spray on flower visitation and reproductive output of two imperiled plants at the wildland-urban interface in the present study. Chamaecrista lineata var. keyensis (Pennell) H.S.Irwin \& Barneby and Linum arenicola (Small) H.J.P. Winkl. are pine rockland endemic species that are proposed for federal endangered listing status under the Endangered Species Act (USFWS 2015). Because these species are rare and limited in geographic distribution, I also studied Pentalinon luteum (L.) B.F.Hansen \& Wunderlin, which is located throughout South Florida and the Caribbean. 


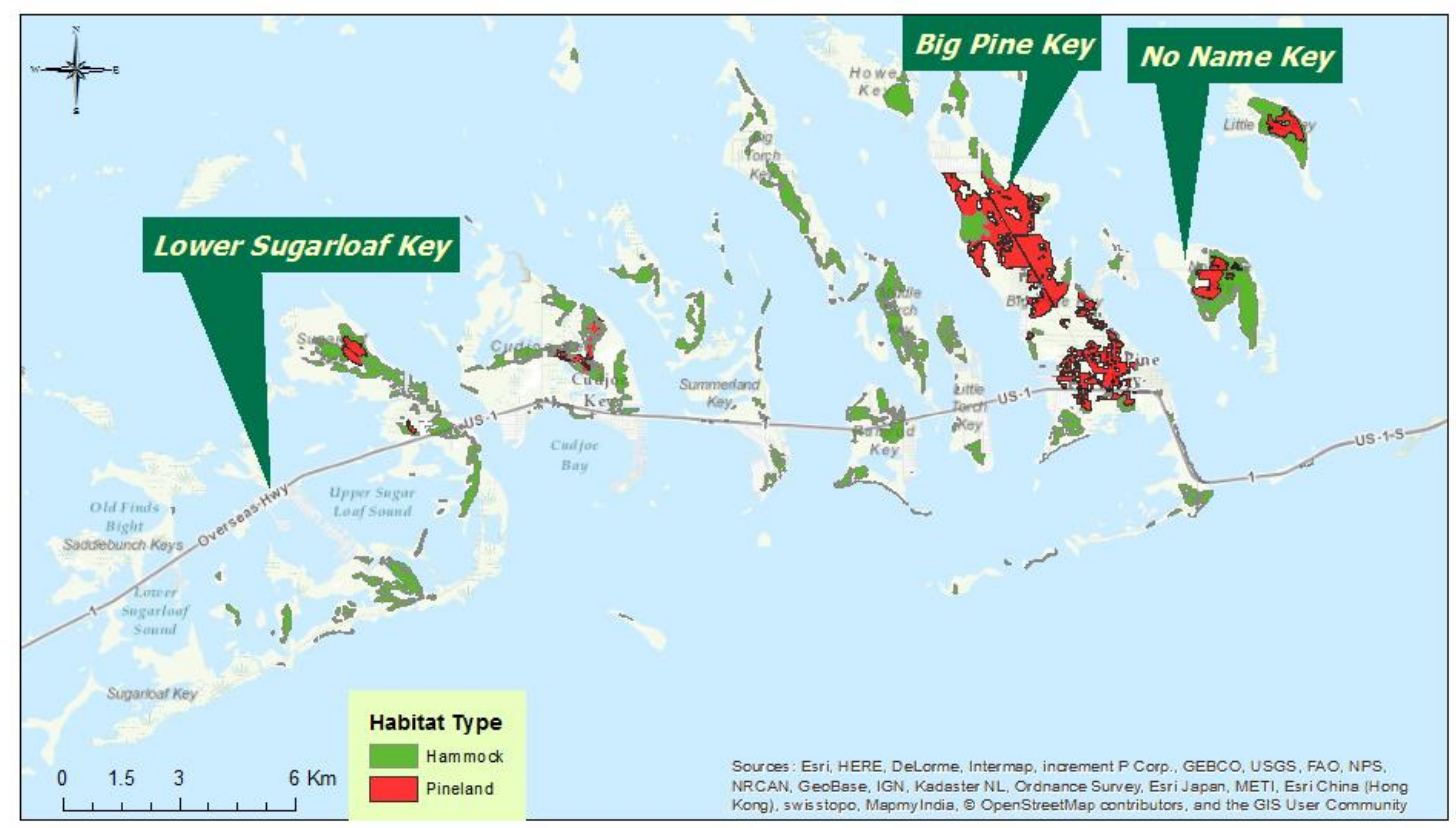

Figure 1. Study location on No Name Key, Big Pine Key, and Lower Sugarloaf Key in the Lower Florida Keys. Red shading is the remaining pine rockland habit in the Keys, and green is rockland hammock habitat.

In the present study, sites for each of the three focal species are on Federal and State conservation land on one or more islands in the Lower Florida Keys, including: Big Pine Key, Lower Sugarloaf Key, and No Name Key (Figure 1). These islands consist of conservation land fragmented by intermittently dispersed residential neighborhoods that seasonally spray insecticides for mosquito control. The frequency of mosquito adulticide missions are highly variable, and are regularly in response to complaints from residents; although spray is also a priority if health risk is high from a vectored disease. Only occasionally did spray missions occur more than once per week at treatment sites. The Florida Keys Mosquito Control District (FKMCD) generally posts the schedule and maps for aerial and truck adulticide missions between 6 and 24 hours before a spray mission. Because of the sporadic and uncertain mosquito spray schedule, I located potential treatment sites near historically sprayed areas (Figures $2-5$ ). The selected control and 
treatment sites varied per species based on location of extant populations, and are therefore described individually for each species. The sites had potential to be sprayed at disproportionate frequencies and some sites had potential to not be treated at all for the 2015 season.

\section{Flower Visitation}

Flower visitation rates can be a good measure of pollinator abundance and changes in populations (Kearns \& Inouye 1993). In addition, quantifying flower visitation rates can account for sub-lethal behavioral effects of insecticides on pollinators, such as feeding cessation or flight inhibition (Coats et al. 1979; Tan 1981b). I conducted timed flower visit observations for each focal plant species to measure direct effects of mosquito insecticide treatments to flower visits. Flower visitor observations for each plant species consisted of 10-minute interval watches of a known number of open flowers from a randomly selected patch of plants. I calculated a visitation rate of number of visits per number of flowers per unit time (Dafni 1992, Kearns and Inouye 1993). When possible, I recorded duration of each flower visit. Floral visitors were identified to species when possible and a voucher specimen of each species was collected and preserved.

Flower visit observations were conducted during the overlap of peak mosquito abatement season and peak flowering season for each species over the summer of 2015 (July and August); P. luteum and L. arenicola had extended periods of observation. Initial flower visitor observations at Lower Sugarloaf (treatment site) began after 
multiple insecticide applications had occurred in order to account for potential delayed effects from insecticide accumulation (Brittain 2010; Zhong et al. 2010). I conducted watches at control and treatment sites for each species the morning after nightly truck insecticide missions or the morning of aerial insecticide missions. Each observation day for a species consisted of at least three 10-minute watches between $0800-1200 \mathrm{~h}$ at each site. Observations occurred only on sunny to slightly cloudy days to exclude visitation difference associated with rain or extreme weather (Kearns \& Inouye 1992). Wind speeds and relative humidity were variable between watches, but a large number of observations occurred with conditions represented at each site to account for this variation. The order of sites for flower visitor observations in any one day were randomly chosen to avoid bias, normally no more than two sites per day. Insecticide treatment applications were replicated three times for $P$. luteum and $L$. arenicola by either truck or aerial application; however, replications of truck and aerial applications were too small to analyze individually.

Because the plant species in the present study flower at different periods and occur at different areas with different spray regimes, methods and results are described individually for each species. For each species, I analyzed for differences in flower visitation rates between sprayed and unsprayed sites after an adulticide application. Flower visitation rate (no. visits/flower/min) were analyzed with Mann-Whitney U tests. All analyses were carried out in SPSS version 23.0 (IBM Corp. 2013). 


\section{Reproductive Output}

Following flowers open during insecticide spray for populations in areas sprayed and areas not sprayed allows for comparisons of fruit set that could reveal any negative effects of pesticides to plant reproduction. Chamaecrista lineata var. keyensis (Liu \& Koptur 2003) and Pentalinon luteum (Koptur unpublished data) require pollination by an external agent for successful reproduction (i.e., fruit set and seed set); therefore, a reduction in flower visitation will likely result in decreased fruit set. For species that automatically self-pollinate without an agent, decreased pollinator visits may not have a significant effect in the short term, even if reproduction is enhanced with visitation.

To determine the indirect effect of ambient mosquito insecticides on plant reproduction, I assessed proportion fruit set by taking simultaneous observations at control and treatment sites. For sites with large populations of focal plant species $(>50$ open flowers on a given day), I randomly selected plants along a 20-meter wide and 400meter long transect. All transects ran parallel to the truck spray route so as not to confound the effect of distance from spray route. The exception to this is one reference control site for each species $1 \mathrm{~km}$ from the road (Figure 3). Control sites have not been treated with insecticides for many years. All individuals marked were reproductively active and at least 5 meters from the nearest neighbor. In addition, all plant species have one-day flowers, to insure that flowers open following insecticide spray could have only been visited after spray occurrence. After insecticide applications, I marked the pedicel of open flowers at treatment and control sites. Within 7-12 days, I revisited marked individuals to determine if flowers were fertilized (i.e., produced fruit with at least one seed) or aborted. Fruit set was analyzed with Chi-square tests with adjusted residuals and 
a Bonferonni corrected p-value for contingency tables larger 2x2 (Beasley \& Schumacker 1995).

\section{Chamaecrista lineata var. keyensis}

Chamaecrista lineata var. keyensis, Big Pine Partridge Pea, is an herbaceous legume (Caesalpinioideae) endemic to pine rocklands in the Lower Keys. In September 2015, this species was proposed by USFWS for federal endangered listing status (USFWS 2015). Extant populations occur only on Big Pine Key within intact pine rockland habitat, and occasionally along disturbed roadsides adjacent to pine rockland (Ross and Ruiz 1996). In the summer of 2015, plants were numerous and reproductive at the few pine rockland sites on Big Pine Key that were not overgrown with shrubs and hardwoods (Figure 2). Plants were also present in shady sites but had fewer reproductive individuals than plants in full sun. Observations indicate peak flowering season from May until August, which coincides with peak mosquito abatement. During the summer of 2015, populations were located at two control sites and three potential treatment sites in protected areas adjacent to residential neighborhoods where mosquito spray applications had been concentrated historically (Figure 2). Control sites had not been treated with insecticides for many years (USFWS personal comm.).

Flowers of $C$. lineata are yellow and slightly bilaterally symmetrical with faint red coloration where the base of the clawed corolla joins the reddish-brown stamens. Pollen is released from poricidal anthers when visited by 'buzz' pollinators (Liu and Koptur 2003). Although self-compatible, flowers will not be pollinated without an 
efficient visitor (Liu \& Koptur 2003), therefore a reduction in flower visitation by buzz pollinators will likely reduce fruit set in $C$. lineata populations exposed to ambient mosquito adulticides. In a study on the breeding system of this species on Big Pine Key, decreased flower visits to $C$. lineata following an insecticide application near residential neighborhoods were observed (Liu \& Koptur 2003).

Flower visitation watches and fruit set observations for plants at all sites took place from late May to mid-August. However, no mosquito adulticide missions occurred on any $C$. lineata occupied habitat during the 2015 flowering season. There was potential for permethrin to have drifted into one patch of $C$. lineata located near Whispering Pines Subdivision in southeast Big Pine Key (Figure 2), although this patch was between 350 and 550 meters from the truck ULV route. Truck spray missions in this subdivision occurred 5/8/2015, 8/1/2015, and 8/12/2015. I conducted flower visitor observations and marked open flowers the morning after the second and the third truck missions, to determine if drift from nearby applications had any direct or indirect effect on pollinators and plant reproduction. I pooled observations for both treatment dates and pooled simultaneous observations for plants not near spray routes. I used a Mann-Whitney U test to compare flower visitation rates between populations and a chi-square test for differences in fruit set proportions. 


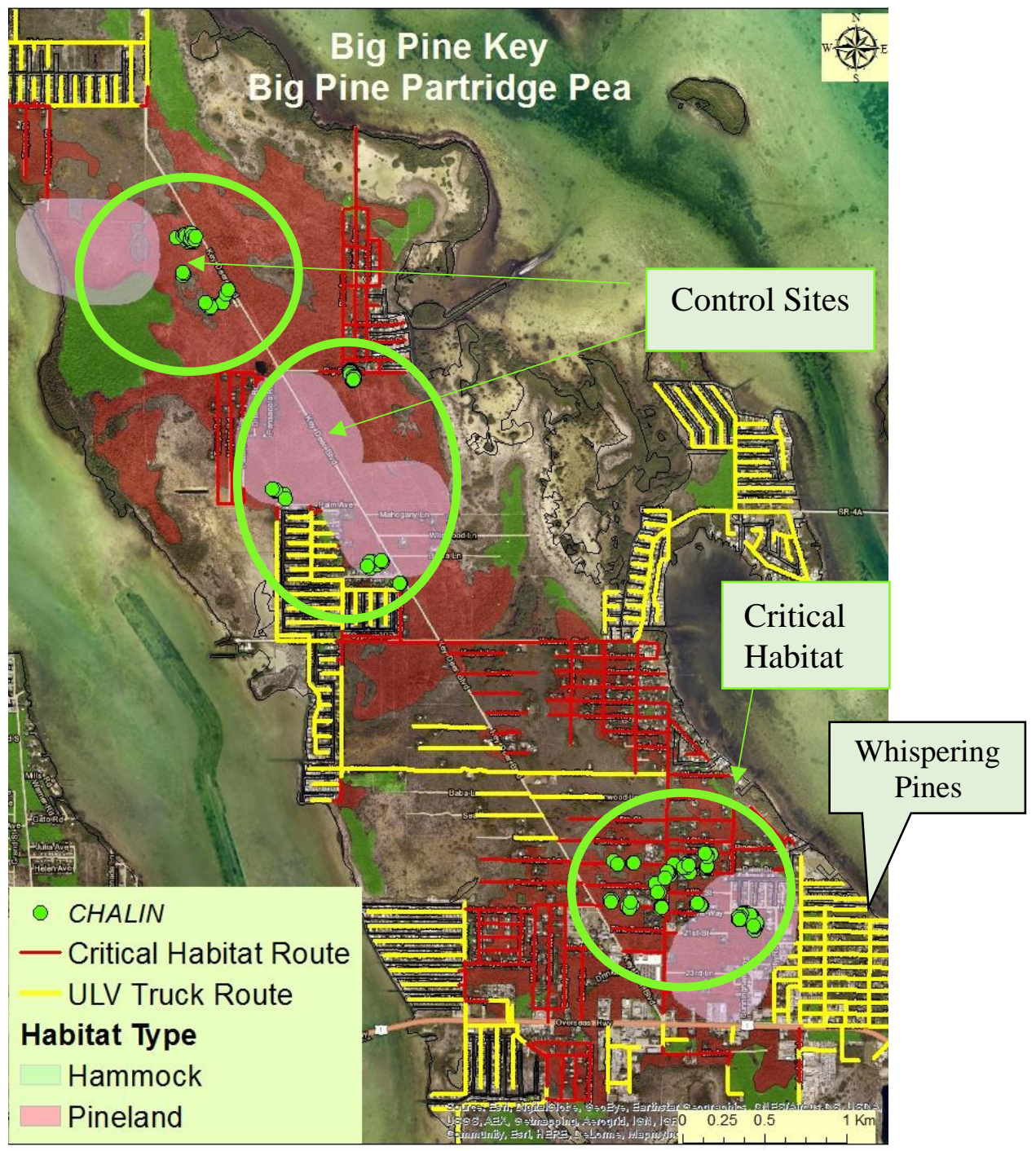

Figure 2. Chamaecrista lineata var. keyensis individuals used in the present study on Big Pine Key. Only Whispering Pines subdivision was sprayed in 2015. Flower visitation rates and proportion fruit set were simultaneously measured for individuals at Control Sites and in the area labeled Critical Habitat (> 350m from spray route) following mosquito insecticide applications at Whispering Pine.

\section{Linum arenicola}

Linum arenicola (Linaceae), Sand Flax, is a small grass-like perennial herb with bright yellow one-day flowers about $1 \mathrm{~cm}$ in diameter. Upon maturity, capsular fruits dehisce and release up to 10 glossy light brownish-yellow seeds. It is an endangered species in Florida and was proposed for federal endangered listing status at the end of my 
2015 field season along with $C$. lineata var. keyensis (USFWS 2015). Linum arenicola is endemic to South Florida and thought to be a pine rockland endemic species (Ross and Ruiz 1999). In the Lower Keys, this species occurs on various edge habitats. Habitat degradation from lack of fire (i.e., increased canopy closure) has likely restricted this species to disturbed roadside and marginal lands (USFWS 2015). It has been extirpated from many other islands in the Lower Keys (Hodges \& Bradley 2006; Ross \& Ruiz 1996; USFWS 2015). In my study, populations were frequently found growing alongside multiple grass species, Agalinis fasciculata, Chamaecrista lineata var. keyensis, Rhyncospora colorota, Euphorbia pergamena, Piriqueta cistoides subsp. caroliniana, and many other low-lying herbs. 


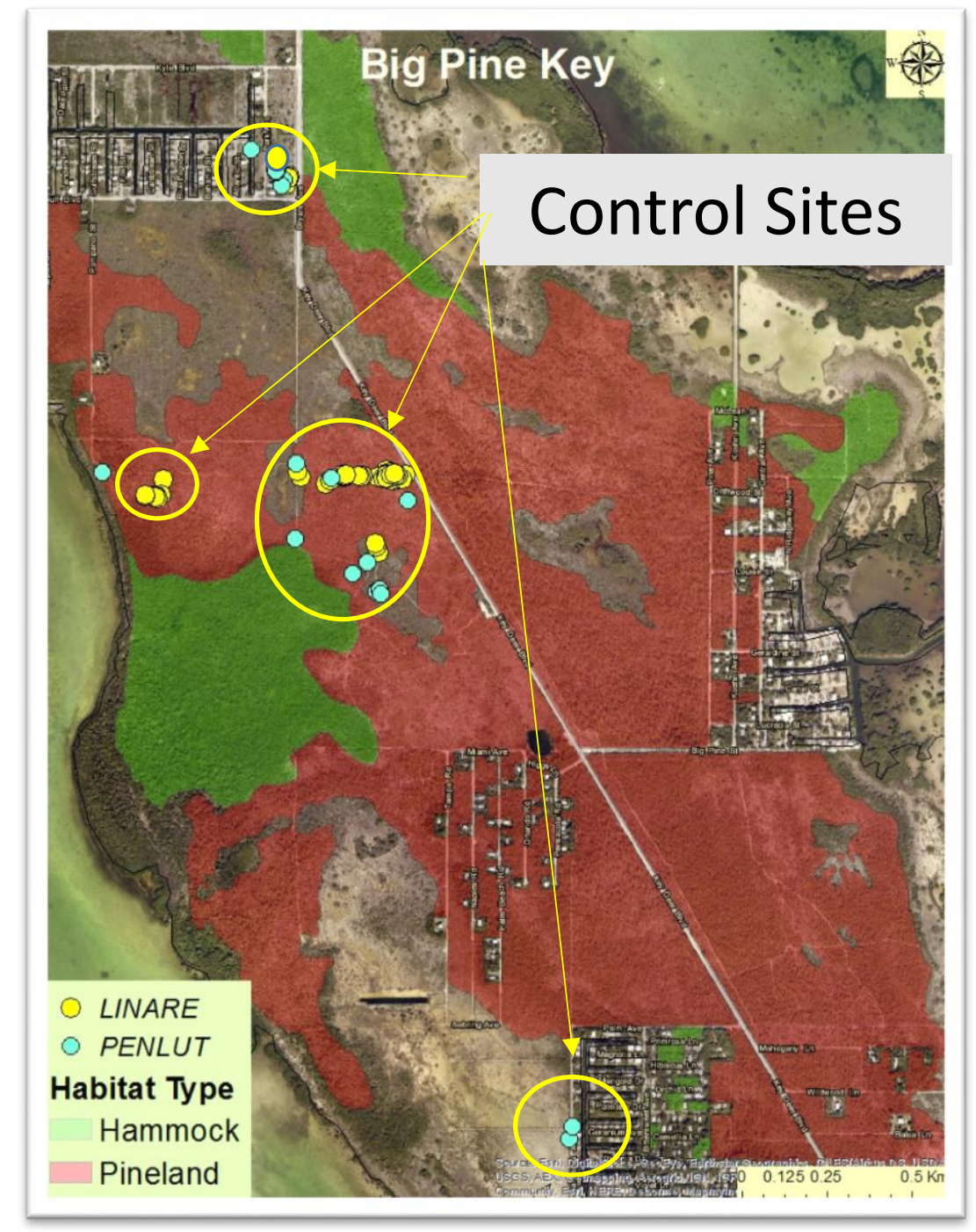

Figure 3. Big Pine Key. Linum arenicola (LINARE) and Pentalinon luteum (PENLUT) control sites within National Key Deer Refuge on Big Pine Key. Sites for both species occurred road-side with one remote reference site for each species.

Observations for L. arenicola took place on two islands with different mosquito abatement regimes. Outside of the South Florida mainland, viable populations of Linum arenicola only occur on Big Pine Key and Lower Sugarloaf Key (Figures 3\&4). I measured flower visitation rates and fruit production at three control sites on Big Pine Key (Figure 3) and one treatment site on Lower Sugarloaf (Figure 4). No mosquito spray 
missions occurred on Big Pine Key in 2014 or 2015 on or near Linum arenicola occupied habitat. Before field observations began on Lower Sugarloaf, 4 aerial missions and 11 ULV truck spray missions had occurred since the beginning of the 2015 mosquito spray season (Appendix A1). In 2015, observations occurred the morning of aerial adulticide missions on July $2^{\text {nd }}$ and August $12^{\text {th }}$, and the morning after a truck mission on July $28^{\text {th }}$. Simultaneous observations were also taken at control sites, within 3 days of each of these treatments. When possible, observations were conducted at intervals greater than two weeks between spray missions. Three additional sampling observations were taken at the beginning of the 2016 mosquito season, from April 1 to May 15, over 150 days since the last spray mission.

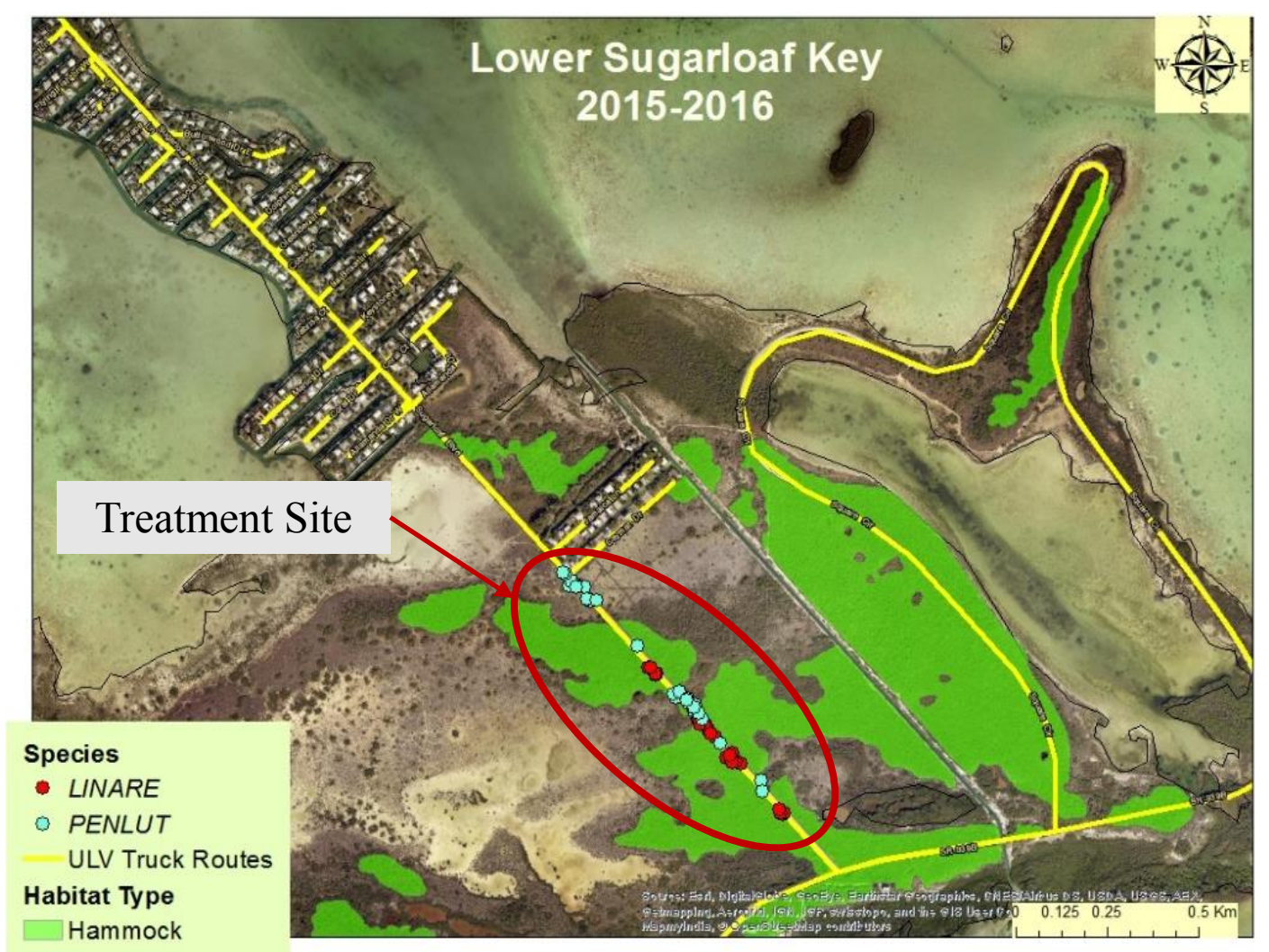

Figure 4. Linum arenicola (LINARE) and Pentalinon luteum (PENLUT) populations along mosquito adulticide ULV truck route on Lower Sugarloaf Key. The route for aerial missions covers the whole island (not shown). 
The breeding system of Linum arenicola was unknown prior to this study, so I conducted exclusion trials to determine if L. arenicola can reproduce in the absence of flower visitors. The reproductive biology of closely related species suggested selfincompatibility and a fly pollinator (Kearns and Inouye 1994). At 0700h, as flowers buds were breaking (but before anthesis), I randomly selected up to 10 plants with open flowers from each of two $10 \mathrm{~m}^{2}$ plots. I marked and bagged flowers to prevent flower visitor access $(n=20)$. Because plants are tall $(36 \mathrm{~cm} \pm 9.8 \mathrm{~cm})$ and wiry, with very small flowers, I bagged the whole stem that bore an inflorescence. The inflorescence was randomly chosen if there were more than one per plant; if there were more than two emerging flowers per plant, only two were randomly marked. Exclusion bags were $12 \mathrm{~cm}$ $\mathrm{x} 8 \mathrm{~cm}$ mesh drawstring bags that allow wind, but prevent flying flower visitors (Kearns \& Inouye 1994). It was perhaps possible for ants to enter from the stem base, but I very rarely saw ants visiting flowers. Visitor exclusion bags were removed before sunset, by which time all flowers had senesced. Seven days later, the plant was revisited to determine for each flower if fruit was set or the flower aborted. Some plants were used again at different trial periods. I repeated this experiment on four occasions throughout July 2015 at one control site, for 80 flowers from 24 plants.

To understand if mosquito insecticides have a direct and/or indirect effect on flower visitation and fruit production in Linum arenicola, I used a modified Before After Control Impact (BACI) design (Stewart-Oaten et al. 1992). The BACI design includes simultaneous measurements at several control sites and a treatment site before the onset of the mosquito spray season and after a spray application has occurred (Table 1). The 
BACI designs are generally used for assessing long-term effects when one impact occurs at only one site, in which multiple measurements are taken over time after the impact. It can also be a useful design for measuring short-term impacts when treatments are replicated at the treatment site along with simultaneous measurements at control sites. Replicates consisted of three mosquito insecticide applications at the treatment site in the middle of the mosquito spray season for flower visitation rate and fruit set observations. Measuring multiple control sites throughout the sampling period accounts for natural pollinator fluctuations across space and time. Taking observations before the mosquito spray season and after multiple spray missions at the treatment site account for changes in flower visitation and fruit set at the particular impact site. Table 1 provides a summary of groups and times that were analyzed for flower visitation rates and proportion fruit set.

\begin{tabular}{|c|c|c|c|}
\hline Site Type & Time Interval & Observation Season \& Year & $\begin{array}{c}\text { Number of } \\
\text { Replicates }\end{array}$ \\
\hline Control \& Treatment & After Spray Missions & Summer 2015 & 3/site \\
Control \& Treatment & Before the Spray Season & Spring 2016 & 3/site \\
Treatment & $\begin{array}{c}\text { Before Spray Season \& } \\
\text { After Spray Missions } \\
\text { Before Spray Season \& } \\
\text { After Spray Missions }\end{array}$ & Summer 2015 \& Spring 2016 & 3/ year \\
\hline
\end{tabular}

Table 1. The Before After Control Impact (BACI) design for investigating direct and indirect effects of mosquito insecticide on Linum arenicola. Summary table lists groups and time intervals that will be analyzed to isolate mosquito spray as the variable responsible for differences in flower visitation and fruit set.

Differences in flower visitation rates between treatment and control groups were analyzed with Mann-Whitney U tests at each time interval and spray replicate. Flower visitation within groups over time, before the spray season $(n=3)$ and after replicate 
applications $(\mathrm{n}=3)$, were analyzed with Kruskal-Wallis tests. I used Mann-Whitney U tests for post-hoc pairwise comparisons between intervals to determine where differences in visitation were significant.

To determine if $L$. arenicola requires flower visitation for reproduction, I compared proportion fruit set from 'bagged' open flowers, in which insect visitation was prevented, to 'exposed' open flowers at the same site. To assess differences in fruit set as a result of mosquito spray activity, I used a Chi-Square cross-tabulations for each set of groups and time periods as discussed for flower visitation rates and as outlined in Table 1.

\section{Pentalinon luteum}

Pentalinon luteum (Apocynaceae), Wild Allamanda, Wild Unction, or Hammock's Viper Tail, is a perennial liana with large yellow tubular flowers and long (from $5-25 \mathrm{~cm}$ each half-fruit) mericarpous fruits that split at the base and nearly meet back up at the tips. Fruits may produce up to several hundred wind dispersed seeds (Koptur unpublished data). This species occurs throughout the Caribbean and South Florida in a variety of habitats. In the Lower Keys it occurs in rockland hammocks, coastal berm/coastal strand, and infrequently in pinelands. Pentalinon luteum plants are self-incompatible, and will only produce fruit and seed when fertilized with pollen from the flower of an unrelated plant (Koptur unpublished data). Flowers are open for one day, from just before sunrise to near sunset, and are visited frequently by long-tongued bees and less frequently by skippers and butterflies in the Lower Keys (personal observation). Many plants were flowering from late May through November in 2015. 
Flower visitation rates and fruit set observations for P. luteum were conducted on Big Pine Key, No Name Key, and Lower Sugarloaf Key. Big Pine Key contained three control sites: two roadside and one remote (Figure 3). The population co-occurring with L. arenicola on Lower Sugarloaf Key was the treatment site (Figure 4). Observations were conducted after the same three adulticide missions as L. arenicola and, when possible, fruit set was observed at intervals greater than two weeks between sprays.

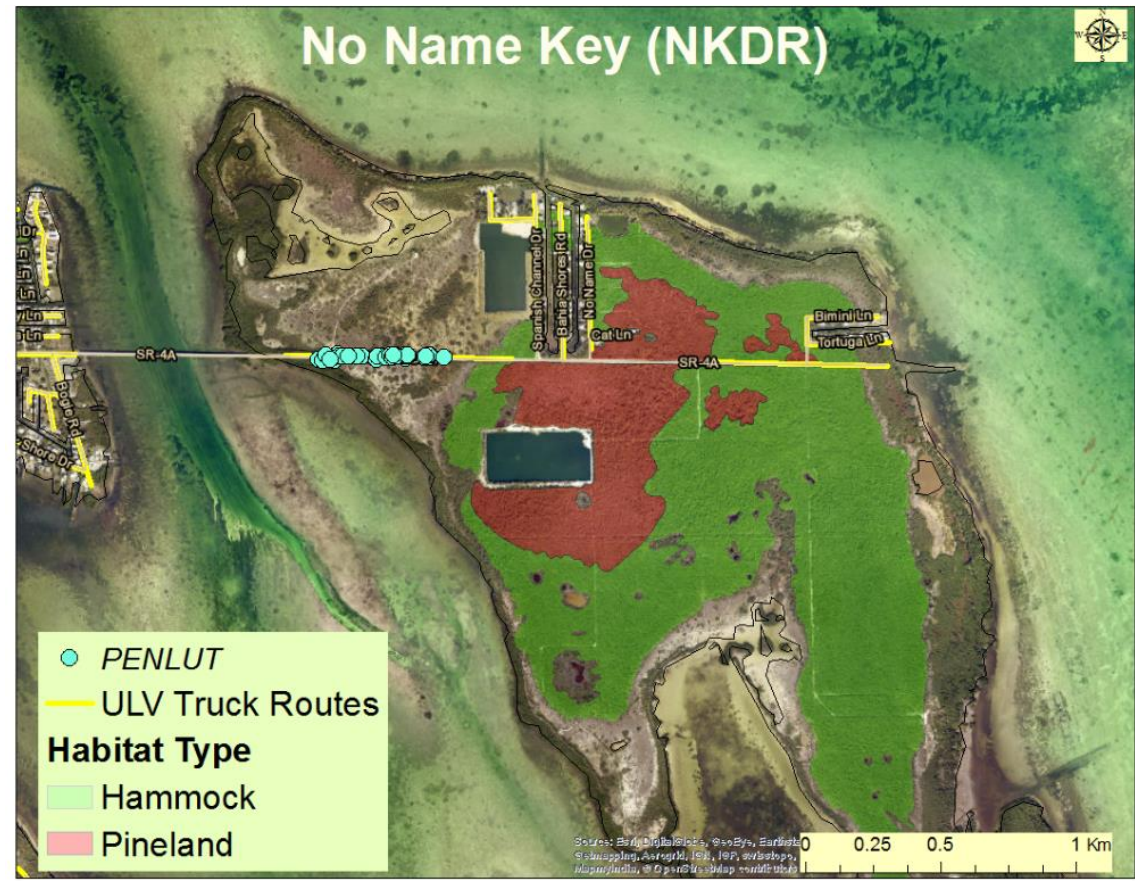

Figure 5. No Name Key. Pentalinon luteum population occurring parallel to the ULV truck route on No Name Key within National Key Deer Refuge boundary

Flower visitation and fruit set analyses for P. luteum were conducted in a similar manner as the BACI design described for Linum arenicola. However, the onset of flowering for $P$. luteum occurred after the first mosquito spray mission, therefore observations before the mosquito spray season were not possible. I compare flower visitation rates and fruit set that were simultaneously observed at control and treatment sites after each insecticide spray. I used Mann-Whitney U tests and Chi-Squared 
analyses, respectively; these include observations for each replicate spray and for fruit set observations $>5$ weeks after treatment to test for recovery between spray missions.

While Lower Sugarloaf was treated multiple times before field observations began (See Appendix 1), No Name Key received only one mosquito truck spray mission in the 2015 spray season. I conducted an additional analysis for observations on the No Name Key population before and after the spray mission to test for differences in flower visitation and fruit set after only one application (Figure 5). Flower visitation rates were analyzed with a Mann-Whitney U test, while fruit set was analyzed with a Chi-squared test in a $2 \times 2$ contingency table.

\section{Results}

\section{Chamaecrista lineata var. keyensis}

Because of the recent critical habitat designation for the endangered Bartram's Scrub Hairstreak Butterfly (Strymon acis bartrami) in late 2014 (USFWS 2014), FKMCD did not apply adulticides near any roads adjacent to pine rockland habitat where Chamaecrista lineata var. keyensis was directly observed. The critical habitat designation for the endangered butterfly includes all pine rockland within National Key Deer Refuge where its sole larval host, Croton linearis, can potentially occur (USFWS 2014). Studies in the Florida Keys prior to the federal listing of Bartram's Scrub Hairstreak indicated that drift from mosquito insecticides are detrimental to the recovery of the imperiled butterflies (Eliazar \& Emmel 1991; Salvato 2001; Hoang et al. 2011; Bargar 2012; USFWS 2014). Because of these studies, critical habitat for Bartram's Scrub Hairstreak includes 'no spray' buffer zones in areas occupied by the endangered butterfly (Figure 2). 
In addition, adulticide applications are limited in areas where Bartram's scrub-hairstreak has not been observed but Croton linearis may occur (unoccupied habitat). Unoccupied critical-designated habitat buffers (Figure 2) limit mosquito insecticide spray to once every 30 days when mosquito landing rates are 'very high' (personal comm. with FKMCD). Regulations also restrict aerial adulticide applications on Big Pine Key to once yearly in the case of emergency situations (personal comm. with FKMCD). This critical habitat coincides with observed occurrences of Chamaecrista lineata var. keyensis throughout $C$. lineata's range.

Because FKMCD spray locations and scheduling of spray missions are sporadic, occur with little notice, and spray routes through critical habitat included recent regulations, times and locations for spray activity were not predictable. I conducted flower visitation and fruit set observations at multiple potential locations on Big Pine Key (Figure 2) every two weeks, however, the only spray activity that occurred near subpopulations of $C$. lineata, was in Whispering Pines subdivision over 350 meters from critical habitat and $C$. lineata occurrences. I observed flower visitors and fruit set after three of the eight spray applications that occurred in this neighborhood (Appendix 1). There was no significant difference in fruit set between areas historically not sprayed for mosquitos and the 'Critical Habitat' $>350$ meters from activity. Because truck spray routes began in the adjacent neighborhood before initial sampling observations took place, before and after measures could not be collected. The decrease, although not significant, in fruit set $(\mathrm{p}$-value $=0.082)$ and flower visitation rates between control and critical habitat is likely attributed to variation in habitat quality between sites from lack of prescribed fire (i.e., canopy closure), and not necessarily from insecticide drift. Although 
not quantified, plants in fire maintained sites and along roadsides had more flowers and less foliage than plants at overgrown sites, which may also affect the rate of flower visitation and fruit set. Before after impact studies, multiple treatment sites with similar distances from spray source, caged pollinator experiments, and/or drift residue collections within pine rockland in the Lower Keys may provide further information on any potential effects of insecticides within buffer zones for critical habitat.

\section{Linum arenicola}

\section{Mosquito Spray and Flower Visitation Rates}

I used visitation rates to open flowers as a proxy to measure changes in pollinator abundance following mosquito insecticide spray (Table 2). Following the BACI design, flower visitation rates were calculated simultaneously at control and treatment groups before the mosquito spray season $(n=4, n=3)$ and after insecticide applications $(n=3, n=4)$ in the middle of the spray season. There was little difference in visitation rates over time at control sites $(\mathrm{p}=.205)$, indicating consistency in visitation rates to open flowers at control sites for all observations June - August 2015 and April - May 2016, after and before the mosquito spray season, respectively. There was a difference in flower visitation rates between treatment and control sites before the mosquito spray season began $(\mathrm{p}=.04)$, indicating some variation in pollinator abundance between sites before spray seasons (Figure 6). However, visitation rates to flowers open after an insecticide spray was substantially lower in flowers exposed to ambient mosquito spray than flowers 
open at unsprayed areas during the same time period $(\mathrm{p}<0.0001)$ and flowers at the same treatment site before the mosquito spray season $(\mathrm{p}<0.001$; Figure 6$)$.

\begin{tabular}{|c|c|c|c|c|}
\hline Groups & Time Interval & $\begin{array}{c}\text { \# of } \\
\text { Flowers }\end{array}$ & Time (min) & $\begin{array}{c}\text { Flower } \\
\text { Visitation } \\
\text { Rates }\end{array}$ \\
\hline Control & After Spray 2015 & 72 & 210 & .0284 \\
Control & Before Spray 2016 & 169 & 314 & .0227 \\
Treatment & After Spray 2015 & 67 & 155 & .0109 \\
Treatment & Before Spray 2016 & 72 & 160 & .0016 \\
\hline
\end{tabular}

Table 2. Summary of Flower Visitation Rates to Linum arenicola and total observation times for control sites at Big Pine Key and the treatment site on Lower Sugarloaf after multiple spray missions during mosquito spray season (July - August 2015) and before the start of mosquito spray season (late March - early May 2016).

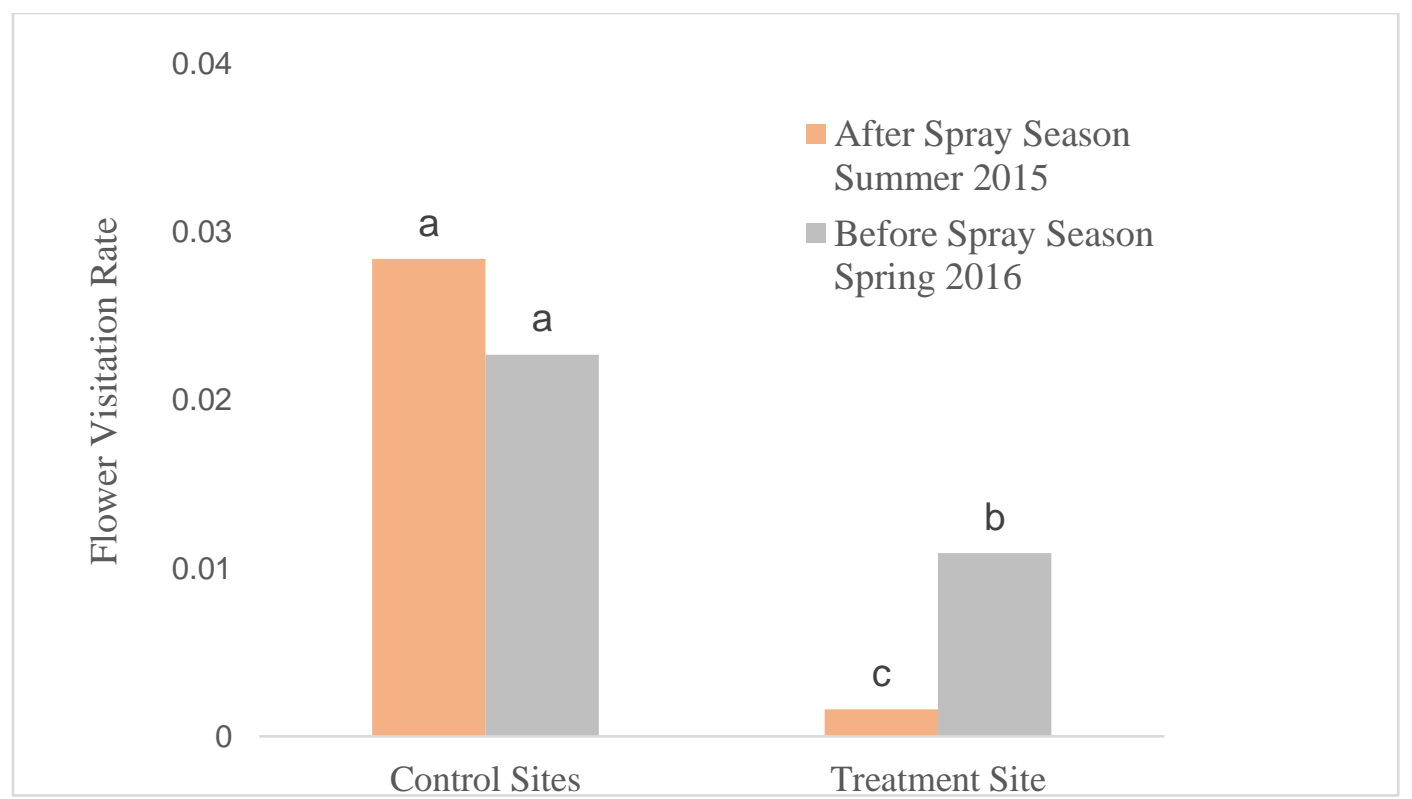

Figure 6. Pollinator Visitation Rates (no. visits/open flower/min) to Linum arenicola populations at control sites (Big Pine Key) and the treatment site (Lower Sugarloaf Key) after multiple seasonal spray missions (July - August 2015) and before the start of mosquito spray season (late March - early May 2016). Means with different letters are significantly different (Mann-Whitney U, $\mathrm{p}<.05$ ) 
Visitors to L. arenicola during this study consisted of an array of small and medium sized bees in the Lower Florida Keys, including several species of Sweat Bees (Tribes Augochlorini and Halictini), Megachile georgica, Anthidiellum notatum ruimaculatum (Megachilidae), and flower flies of the genus Ocyptamus (Syrphidae). Occasionally, small butterflies and skippers visited flowers, but they were not consistent and visited for very short durations (1sec. \pm 1$)$.

\section{Breeding system of Linum arenicola}

Flower manipulation experiments to prevent flower visitors conducted in the summer of 2015 indicate that Linum arenicola is self-compatible and can self-pollinate in the absence of flower visitors. Approximately $74 \%$ of flowers enclosed in mesh bags produced fruit $(\mathrm{n}=57)$, indicating a high degree of automatic self-pollination. However, self-pollination is facultative in L. arenicola. When flowers are visited and pollen is deposited on the stigma, the whole corolla abscises as a unit. If pollen is not deposited by the end of the flowering period (between 1200 and 1500h of the same day), the flower senesces, and the corolla matts up and twists the filaments, causing the anthers to come into contact with the stigma and deposit self-pollen (personal observations). The senesced petals usually turn white and can remain matted for several days. It is also likely that wind or rain may facilitate mechanical pollination.

Open flowers 'exposed' to potential visitors may have had increased fruit set by increasing the possibility of pollen movement between or within flowers. Bagged flowers that prevented flower visitors had a significantly lower proportion fruit set than flowers open under natural conditions $\left(\mathrm{p}<0.01, \mathrm{X}^{2}=8.025, \mathrm{df}=1\right.$; Figure 7). Interestingly, fruit 
set proportion in bagged flowers did not significantly differ from mean proportion of flowers open at treatment sites following a mosquito insecticide application $\left(\mathrm{p}>.05, \mathrm{X}^{2}=\right.$ 1.72 , df $=1$ ). Observations and exclusion trials are limited means of understanding the breeding system. Further controlled studies on the breeding system are necessary to elucidate the mechanisms for self-pollination, as well as to understand how much crosspollination takes place under non-sprayed conditions. However, for the importance of this study, my exclusion experiments demonstrated that flowers will set fruit without visitation, and access to flower visitors increase fruit set.

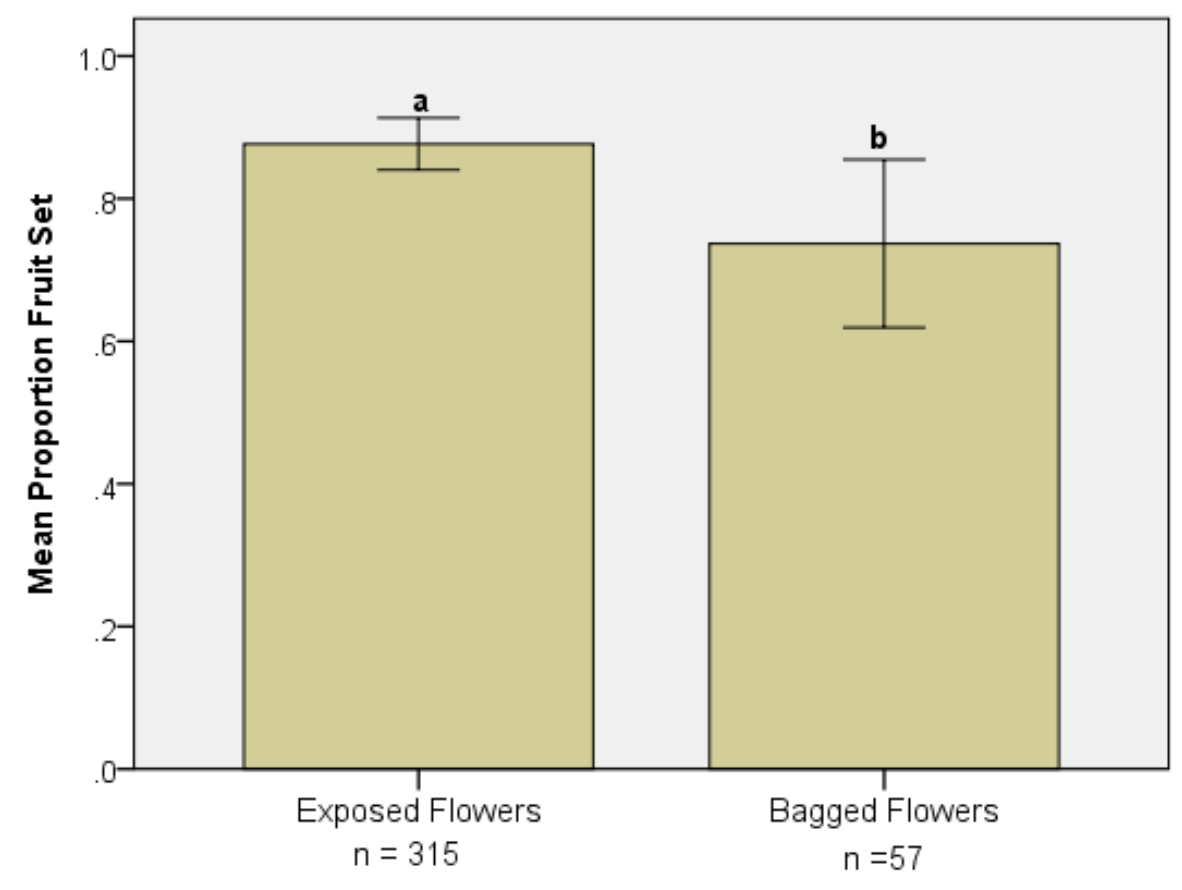

Figure 7. Manipulation experiments on Linum arenicola flowers comparing fruit set with 'exposed' open flowers and 'bagged' open flowers to prevent flower visitation. Means with different letters are significantly different (Chi-square, $\mathrm{p}<.01$ ) 


\section{Linum arenicola}

Mosquito Insecticide Spray and Proportion Fruit Set

To determine if mosquito insecticides have an immediate indirect effect on Linum arenicola, a self-pollinating species, I measured and compared proportion fruit set at control sites on Big Pine Key and the treatment site on Lower Sugarloaf Key before initiation of the mosquito spray season and after multiple insecticide applications in the middle of the spray season. Sample replicates for the control group before the onset of the first mosquito spray application $(n=3)$ were not significantly different from each other $\left(p=0.738, X^{2}=0.607\right)$, nor were the sample replicates $(n=3)$ for observations that occurred after mosquito spray application dates $\left(p=0.914, X^{2}=0.012\right)$; therefore, samples were pooled for observations occurring before spray treatments and for observations occurring after spray dates. Sample replicates were also pooled for treatment sites before the spray season $\left(\mathrm{p}=0.950, \mathrm{X}^{2}=0.102\right)$ and for replicates after the spray season $(\mathrm{p}=0.861)$. 


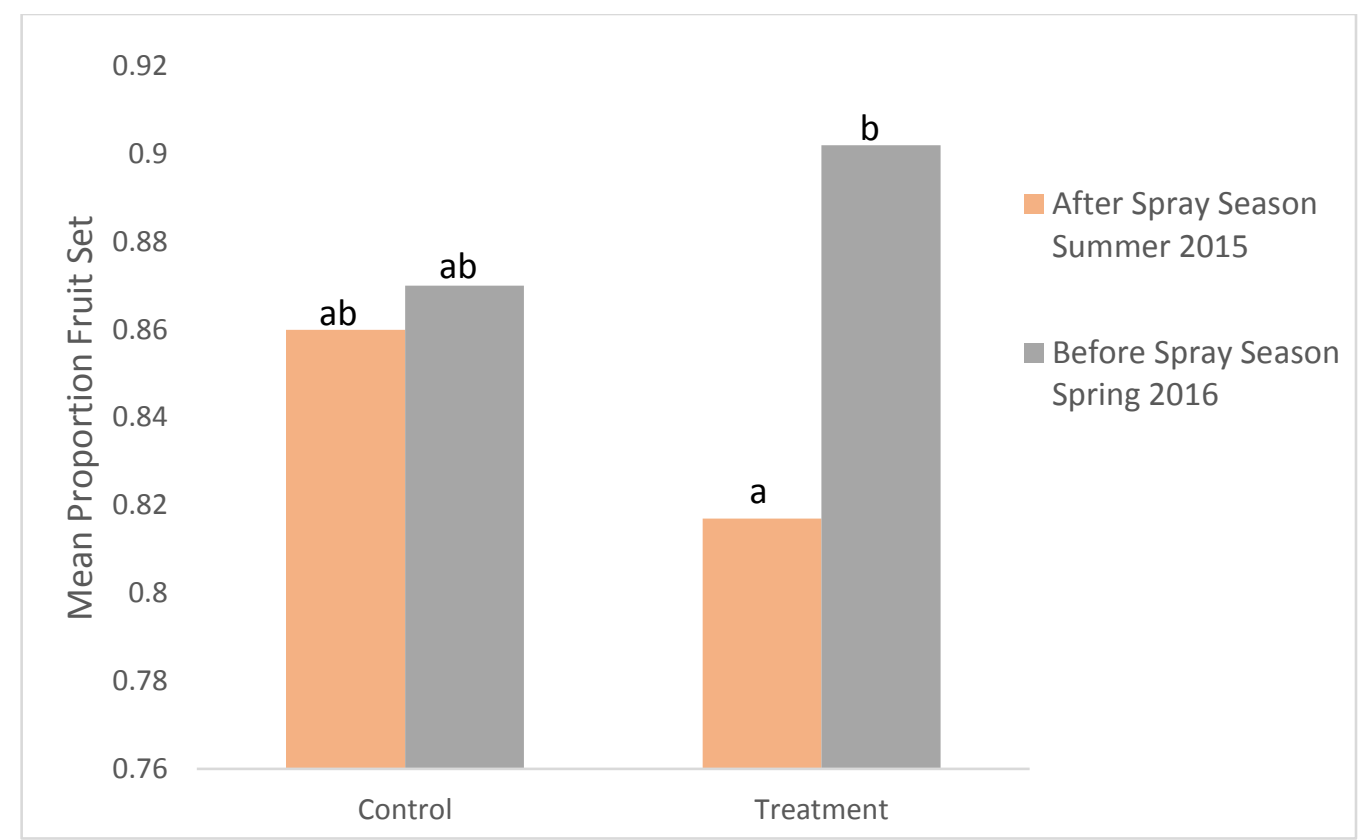

Figure 8. Mean Proportion Fruit Set for Linum arenicola populations at control sites (Big Pine Key) and the treatment site (Lower Sugarloaf Key) after multiple seasonal spray missions (July - August 2015) and before the start of mosquito spray season (late March - early May 2016).

Means with different letters are significantly different $($ Chi-square, $p<.05)$

Fruit set proportions did not differ over time under non-spray conditions, but did differ over time at the sprayed location (Figure 8). Proportion fruit set between the treatment and control group before the spray season was not significantly different, indicating little difference in fruit set between sites under non-sprayed conditions. Fruit set was higher at non-sprayed sites than at treatment sites after multiple insecticide sprays, but the difference was not significant. However, within the treatment site, fruit set was significantly lower after exposure to mosquito spray than before the spray season $(\mathrm{p}<.05)$. Considering the high degree of automatic self-pollination in Linum arenicola without flower visitation (Figure 7), any reduction in fruit set after mosquito insecticide spray may be substantial for this species. 


\section{Pentalinon luteum}

Mosquito Insecticide Spray and Flower Visitation Rates

As in Linum arenicola, flower visitation rates to Pentalinon luteum were used as a proxy to compare pollinator abundance after insecticide applications in areas treated with mosquito insecticides and areas that are not treated. Because seasonal flower initiation in $P$. luteum began after the mosquito spray season for this study, flower visit observations included simultaneous measurements at the Big Pine Key control sites and the Lower Sugarloaf Key treatment site (Figures $3 \& 4$ ) after multiple spray applications for the 2015 mosquito spray season (Appendix 1).

There was little variation in visitation rates to P. luteum within control sites, indicating consistency in visitation rates throughout the sampling period. Visitation rates were significantly lower to $P$. luteum flowers open after insecticide spray applications at treatment sites than visitation rates to flowers open at the same time at untreated sites (Figure 9). For the population at the treatment site, there was a significant increase in visitation rates 5 to 10 weeks after the spray season concluded. Although there was an increase at the treatment site in flower visitation rates between spray missions when compared to visitation rates immediately following an insecticide spray, it was still substantially lower still than the visitation rates at the control sites. Table 3 provides a summary of flower visitation rates to Pentalinon lutem at all sites and observations periods. 


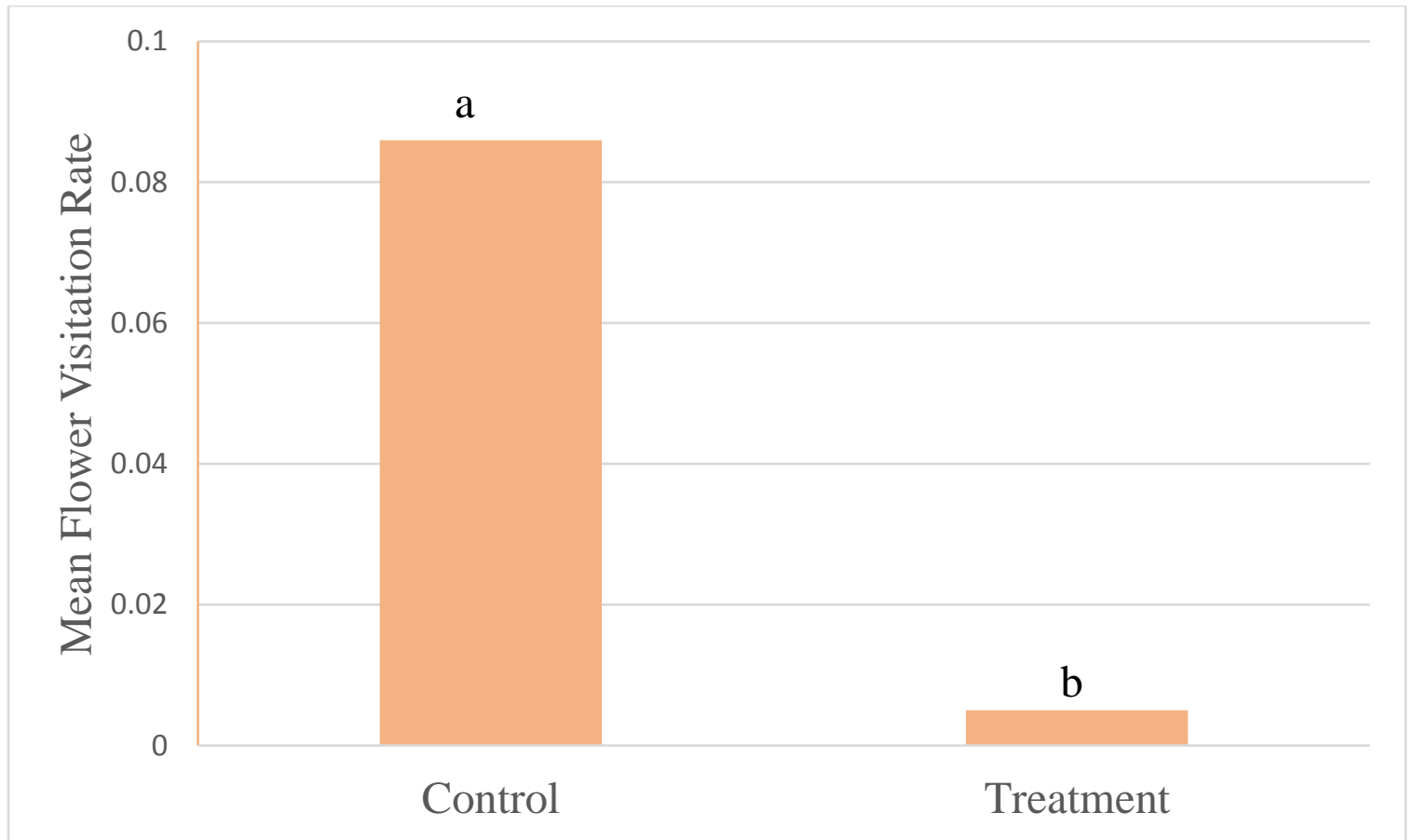

Figure 9. Flower Visitation Rates (no. visits/open flower/min) to Pentalinon luteum populations at control sites (Big Pine Key) and the treatment site (Lower Sugarloaf Key) after multiple seasonal spray missions (July - October 2015). Means with different letters are significantly different (Mann-Whitney $\mathrm{U}, \mathrm{p}<.05$ )

\begin{tabular}{|c|c|c|c|c|}
\hline Groups & Time Interval & $\begin{array}{c}\# \text { of } \\
\text { Flowers }\end{array}$ & Time (min) & $\begin{array}{c}\text { Flower } \\
\text { Visitation } \\
\text { Rates }\end{array}$ \\
\hline Control & After Spray 2015 & 72 & 175 & .0860 \\
Treatment & After Spray 2015 & 61 & 105 & .0010 \\
Treatment & $>$ 14days after Spray (2015) & 72 & 160 & .0063 \\
No Name Key & Day Before Spray & 9 & 85 & .0212 \\
No Name Key & After One Spray & 13 & 50 & .0123 \\
\hline
\end{tabular}

Table 3. Summary of flower visitation rates (no. visits/open flower/min) to Pentalinon luteum and observation times. Control sites at Big Pine and treatment site on Lower Sugarloaf included multiple spray missions during mosquito spray season (July - August 2015). Flower visitation rates on No Name Key the day before and the day after the one insecticide spray mission in 2015 were included in a separate analysis.

In my study, $P$. luteum was visited primarily by skippers, butterflies, and longtounged bees, including Euglossa dilemma (Tribe Euglossini), a potentially invasive 
green orchid bee from Mexico and Central and South America (Liu \& Pemberton 2009).

E. dilemma was not previously documented in the Lower Keys, although its presence on the mainland has been known since 2003 (Skov \& Wiley 2005), likely indicating recent migration to the southernmost tip of Florida. This long-tonged bee was the primary flower visitor during observations for this study. Pollinator efficiency of the orchid bee to P. luteum is unknown, but this species has also been documented to visit closely related plant species with similar shaped flowers, such as Allamanda neriifolia, a horticultural plant common in South Florida (Pemberton and Wheeler 2006).

\section{Pentalinon luteum}

\section{Mosquito Insecticide Spray and Fruit Set}

Comparison of proportion fruit set between treated and untreated sites lets me measure if ambient mosquito insecticide spray had an indirect effect on plant reproduction. Because Pentalinon luteum is a self-incompatible species (Koptur unpublished data), reduced flower visitation will likely result in pollen limitation and a reduction in reproductive output. Simultaneous measurements were taken for populations at sites that were treated and untreated immediately following an insecticide application for three spray replicates. While there was no significant difference in proportion fruit set at control sites over the sampling period, there was a significant difference in fruit set between the Lower Sugarloaf treatment site and the Big Pine Key control sites at each replicate spray treatment $(\mathrm{p}<0.01 ;$ Figure 10$)$. 


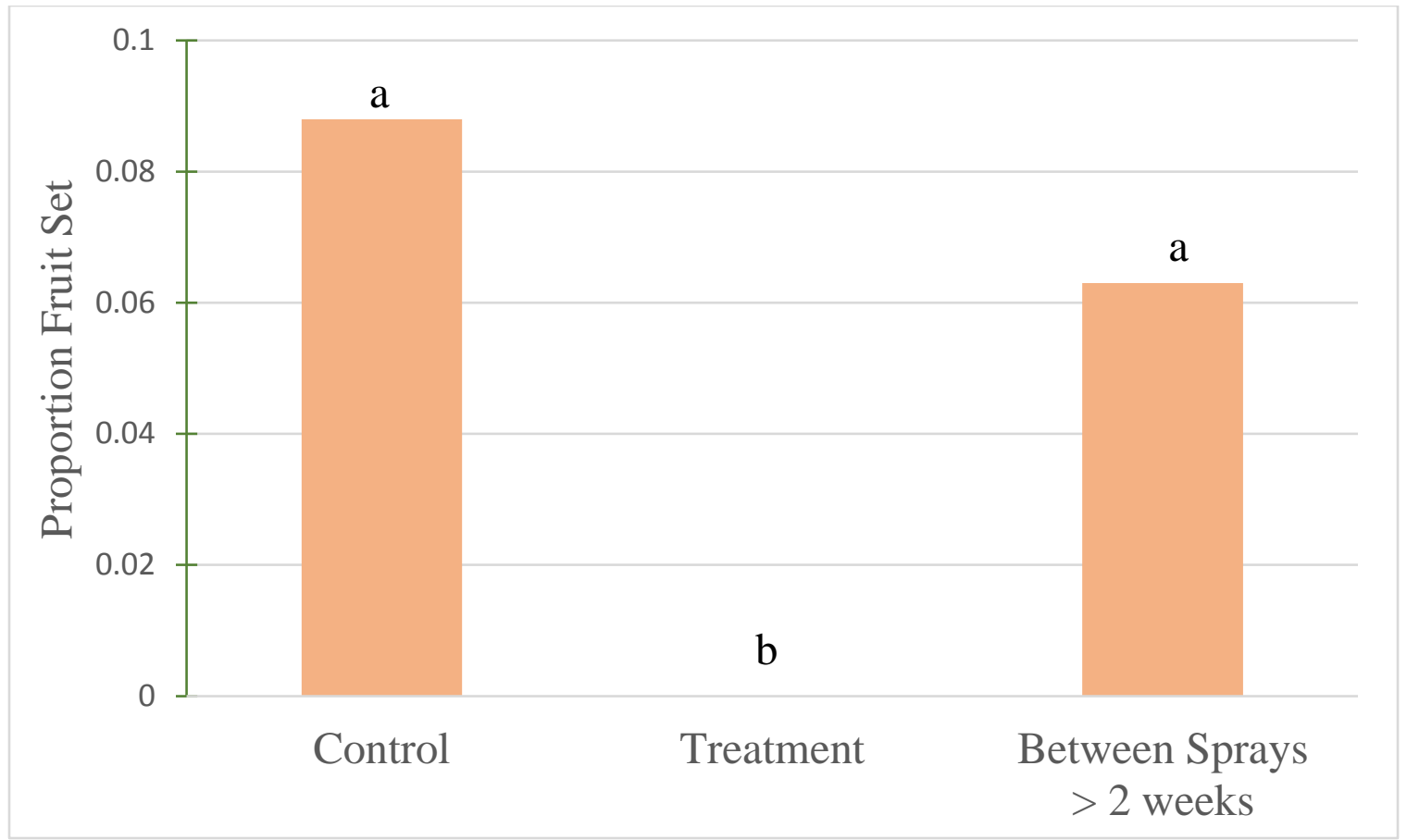

Figure 10. Proportion fruit set for Pentalinon luteum at Big Pine Key control sites and Lower Sugarloaf Key treatments sites following insecticide spray and 14 days after spray activity. Means with different letters are significantly different (Chi-square, $\mathrm{p}<.05$ )

Additionally, observations were taken at the two-week time interval between aerial spray 1 and truck spray 2 for the sampling period. Chi-square comparisons between proportion fruit set in the treatment population immediately following insecticide spray, observations two weeks after spray at sprayed sites, and proportion fruit set simultaneously taken at control sites, produced a $3 \times 2$ contingency table, in which adjusted residuals were used for post-hoc analysis between groups with Bonferonni corrected p-values for each variable contributing to the overall analysis (Beasley \& Schumacker 1995). Results of the Chi-squared analysis indicate a significantly higher proportion fruit set in $P$. luteum three weeks after an insecticide application (Figure 10) compared to flowers open following an insecticide application. In addition, there was no significant difference in fruit set between the control group and flowers open two weeks 
after a spray activity (Figure 10). Additional sampling dates at various extended intervals between spray are necessary to strengthen this analysis, but results could suggest recovery of indirect effects (i.e., increase in reproduction resulting from increased foraging behavior) of mosquito insecticide spray on fruit production after three weeks between sprays.

\section{Flower visitation and Fruit Set Before and After One Insecticide Spray}

Studies indicate that pesticide bioaccumulation may influence the degree of lethality to non-target invertebrates. Multiple insecticide treatments within the spray season may result in bioaccumulation of pesticides, in which pollinators experience lethality more readily than when exposed to one or infrequent treatments in the spray season (Brittain 2010, Zhong et al. 2010). I analyzed flower visitation rates and proportion fruit set for Pentalinon luteum at No Name Key to further test if only one insecticide treatment in a season can have an effect on pollinators. No Name Key was treated with insecticides only once during the 2015 mosquito control season, therefore, I monitored open flowers the day before and flowers open the day after an evening truck spray. Although flower visitation and fruit set was significantly lower for Pentalinon luteum after multiple insecticide sprays at Lower Sugarloaf Key (Figures $9 \& 10$ ), one spray treatment did not have a significant effect on flower visitation rates (Figure 11) or proportion fruit set (Figure 12) between observations before spray and after spray activity. 


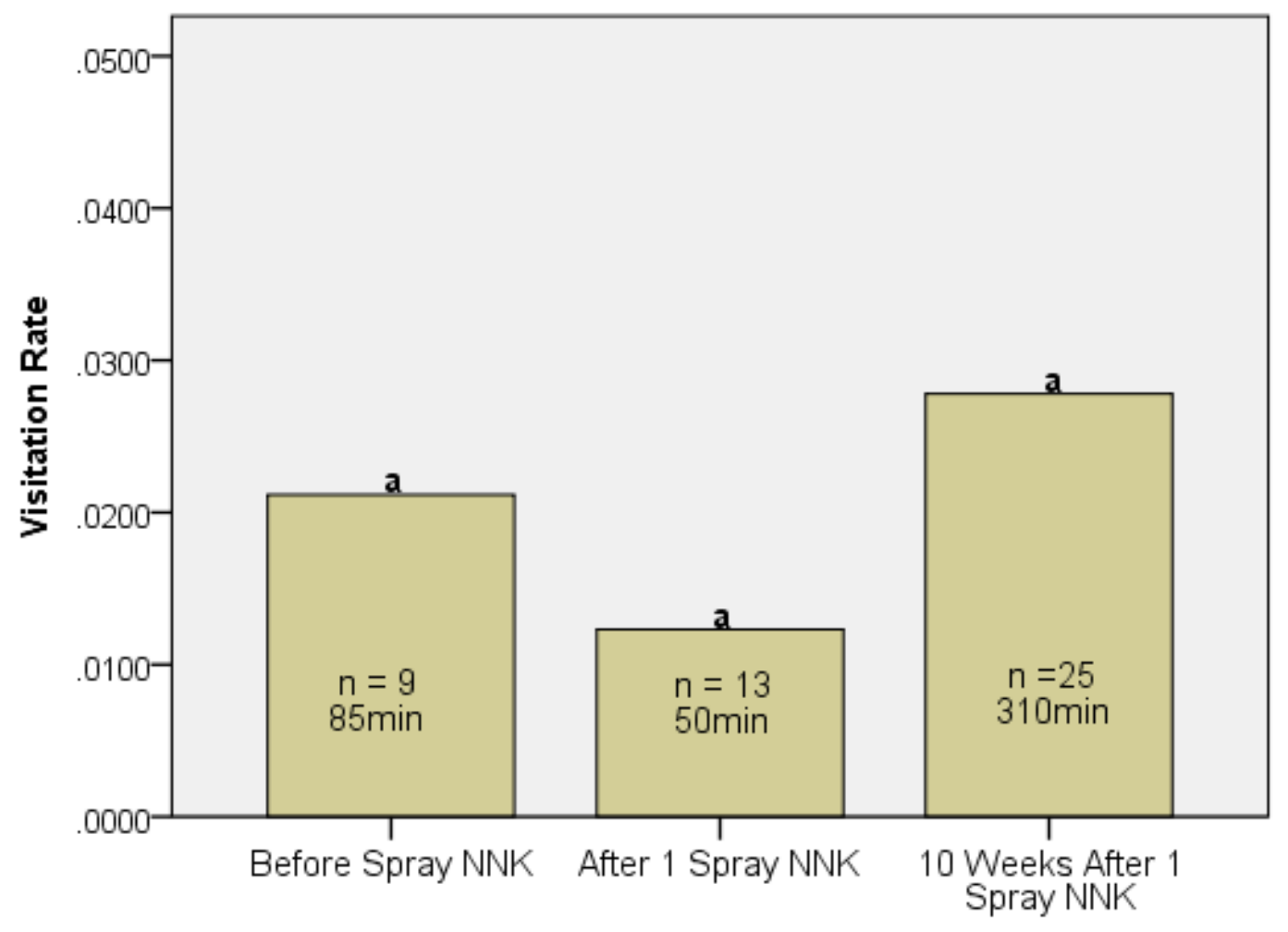

Mann-Whitney U: $p=.162$

Figure 11. Flower visitation rates to open flowers of Pentalinon luteum on No Name Key, the day before, the day after, and 10 weeks after a mosquito insecticide application on this site. Means with different letters are significantly different (Chi-square, $p<.05)$ 


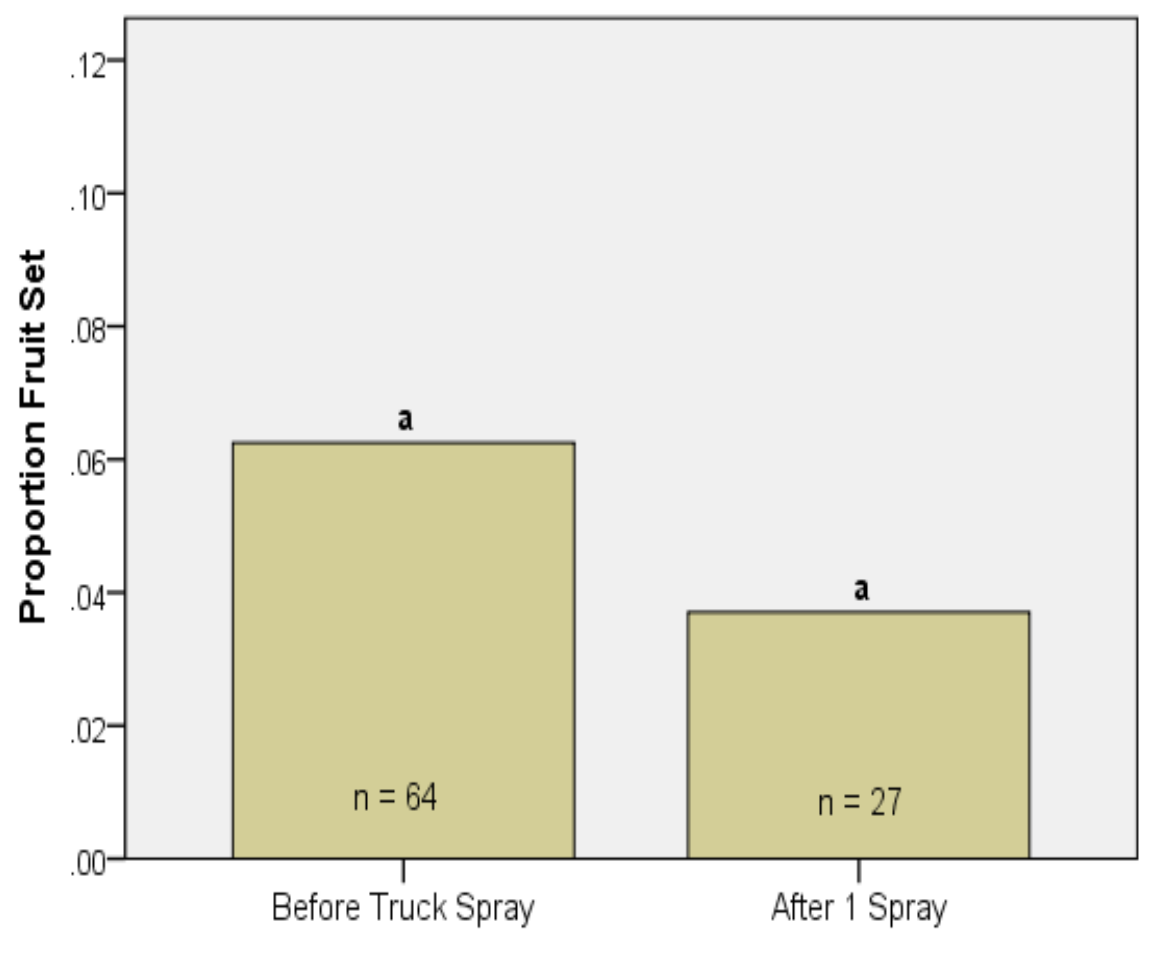

Chi-Square: $p=.533$

Figure 12. Proportion fruit set of open flowers of Pentalinon luteum on No Name Key, the day before and the day after a mosquito insecticide application on this site. Only one application occurred on No Name Key for the spray season. Means with different letters are significantly different (Chi-square, $\mathrm{p}<.05$ )

\section{Discussion}

Understanding the effects of mosquito spray on obligate relationships between pollinators and plants may provide insight to management practices to increase overall success of pollination, thereby preventing extinction of imperiled plants. Knowledge of the reproductive strategies for plant species of concern is imperative to determine if insecticide spray can have a potential indirect effect on reproduction. Pollinator exclusion experiments are limited measures of understanding the breeding system, but can answer 
two important questions for determining if mosquito insecticides have an indirect effect on fruit set: is fruit set dependent on flower visitation?, and if a species can self-pollinate, does visitation enhance fruit set? For species that automatically self-pollinate, decreased pollinator visitation may not have an apparent effect on fruit set. Linum arenicola readily produced fruit when flowers were 'bagged' (i.e., pollinators were excluded), however reproductive output was higher for plants with flowers accessible to pollinators in untreated areas. Despite its ability to self-pollinate in absence of pollinators, L. arenicola reproduction was negatively affected by mosquito spray applications. Further investigation on the breeding system of L. arenicola is necessary to determine long-term effects of self-pollination when flower visitation rates are decreased from ambient broadspectrum insecticides. Although studies suggest that flowers of ruderal herbaceous species may be visited less frequently than plants with more specialized pollination systems.

Direct effects of mosquito insecticides were apparent for plant species exposed to ambient mosquito spray. Visitation rates to flowers of L. arenicola and P. luteum were significantly lower after insecticide applications than visitation rates to flowers in unsprayed areas. For L. arenicola, there was a lower visitation rate at the treatment site before the spray season as compared to simultaneous observations at the control sites, however, this decrease was only slight when compared to the decrease in visitation between sites after mosquito spray, and for before and after observations within the treatment site. It is possible that there is natural variation in pollinator abundance between islands, or that pollinator populations are unable to fully recover between mosquito spray seasons on Lower Sugarloaf Key. For flowering plants that benefit from pollinator 
visitation, and particularly species like $P$. luteum that will not produce fruit when unvisited, decreased visitation may indirectly affect reproduction by decreasing pollen deposition. Although flower visitation may rates may rebound after a few weeks between spray, as shown for $P$. luteum, for sites that are sprayed frequently or for flowering plants with short flowering periods, decreased flower visitation may have very strong negative effects on plant fitness.

Self-incompatible species at the wild-land urban interface are particularly vulnerable to broad-spectrum mosquito insecticides, as evident in Pentalinon luteum. When flower visitation rates were lower after a mosquito insecticide spray, fruit set rates were also significantly lower. Though $P$. luteum is not a rare species, per se, it can be a good model indicator of potential consequences of ambient mosquito insecticide on selfincompatible species.

As current agreements between USFWS and Florida Keys Mosquito Control District (FKMCD) stand, Chamaecrista lineata var. keyensis only occurs in critical habitat and may be buffered from any apparent negative effects to reproduction from mosquito insecticide drift. FKMCD did not perform any aerial or truck adulticide applications within 300 meters of known viable $C$. lineata populations in 2015 . The population in the 'no spray' zone adjacent to Whispering Pines Subdivision was shown to not have a significantly different fruit set value from other populations far from potential drift. Lack of truck adulticide missions in unoccupied critical habitat could have been a result of the unusual drought in the early summer, which decreased FKMCD spray activity throughout the Lower Keys. However, further investigation is needed, as adulticide regimes seasonally vary and can depend on health risks or population 
explosions of disease vector and nuisance mosquitos. In addition, USFWS issues permits to FKMCD for mosquito abatement routes and frequency on a yearly bases, so these variable may change over time. A multi-season study could capture yearly differences. From this one season study, it is apparent that 2015 critical habitat regulations for Bartram's scrub-hairstreak buffer truck ULV insecticide drift from Chamaecrista lineata var. keyensis populations and its pollinator guild by restricting mosquito insecticide activity on pine rockland habitat.

As new diseases pose threats to human health in south Florida, the pressure to control mosquito vectors by chemical means will likely increase. However, alternative methods (such as larvicides, genetically modified mosquitos, and biocontrol management) may prove beneficial to the continued cooperation between plants and pollinators, while providing relief from nuisance and potential disease vector mosquitos. 


\section{References}

Allen-Wardell, G., Bernhardt, P., Bitner, R., Burquez, A., Buchmann, S., Cane, J. et al. (1998). The Potential Consequences of Pollinator Declines on the Conservation of Biodiversity and Stability of Food Crop Yields. Conservation Biology, 12, 8-17.

Antwi, F.B. \& Reddy, G.V.P. (2015). Toxicological effects of pyrethroids on non-target aquatic insects. Environmental toxicology and pharmacology, 40, 915-923.

Arena, M. \& Sgolastra, F. (2014). A meta-analysis comparing the sensitivity of bees to pesticides. Ecotoxicology, 23, 324.

Bargar, T.A. (2012). Risk assessment for adult butterflies exposed to the mosquito control pesticide naled. Environmental Toxicology and Chemistry, 31, 885-891.

Beasley, T.M. \& Schumacker, R.E. (1995). - Multiple Regression Approach to Analyzing Contingency Tables: Post Hoc and Planned Comparison Procedures. - The Journal of Experimental Education, 64, - 79.

Bond, W. (1994). Do mutualisms matter? Assessing the impact of pollinator and disperser disruption on plant extinction. Philosophical Transactions of the Royal Society B: Biological Sciences, 344, 83-90.

Bradbury, S.P. \& Coats, J.R. (1989). Comparative toxicology of the pyrethroid insecticides. Reviews of Environmental Contamination and Toxicology (ed G.W. Ware), pp. 133-177. Springer New York, New York, NY.

Breidenbaugh, M.S. \& Szalay, F.A.D. (2010). Effects of Aerial Applications of Naled on Nontarget Insects at Parris Island, South Carolina. Environmental Entomology, 39, 591-599.

Breidenbaugh, M.S., Haagsma, K.A., Wojcik, G.M. \& de Szalay, F.A. (2009). Efficacy of Aerial Spray Applications Using Fuselage Booms on Air Force C-130H Aircraft Against Mosquitoes and Biting Midges. Journal of the American Mosquito Control Association, 25, 467-473.

Brittain, C., Bommarco, R., Vighi, M., Barmaz, S., Settele, J. \& Potts, S.G. (2010). The impact of an insecticide on insect flower visitation and pollination in an agricultural landscape. AFE Agricultural and Forest Entomology, 12, 259-266.

Brittain, C.A. (2010). Impacts of a pesticide on pollinator species richness at different spatial scales. Basic and Applied Ecology, 11, 106; 106-115; 115.

Buchmann, S.L. \& Nabhan, G.P. (1997). The forgotten pollinators. Island Press. 
Carroll, S. \& Loye, J. (2006). Invasion, Colonization, and Disturbance; Historical Ecology of the Endangered Miami Blue Butterfly. Journal of Insect Conservation, 10, 13-27.

Charlesworth, D. \& Charlesworth, B. (1987). Inbreeding Depression and its Evolutionary Consequences. Annual Review of Ecology and Systematics, 18, 237-268.

Chen, L. (2009). Habitat destruction and the extinction debt revisited: The Allee effect. Mathematical biosciences, 221, 26; 26-32; 32.

Coats, J.R., Symonik, D.M., Bradbury, S.P., Dyer, S.D., Timson, L.K. \& Atchison, G.J. (1989). Toxicology of synthetic pyrethroids in aquatic organisms: An overview. ETC Environmental Toxicology and Chemistry, 8, 671-679.

Coats, S.A., Coats, J.R. \& Ellis, C.R. (1979). Selective Toxicity of Three Synthetic Pyrethroids to Eight Coccinellids A Eulophid Parasitoid, and Two Pest Chrysomelids. Environmental Entomology, 8, 720-722.

Connell, D.W. (1999). Introduction to Ecotoxicology. Wiley-Blackwell, Malden, Mass.

Connelly, C.R. \& Carlson, D.B. (eds) (2009). Florida Mosquito Control: The State of the Mission as Defined by Mosquito Controllers, Regulators, and Environmental Managers. Florida Coordinating Council on Mosquito Control., University of Florida, Institute of Food and Agricultural Sciences, Florida Medical Entomology Laboratory.

Dale, P.E.R. \& Knight, J.M. (2008). Wetlands and mosquitoes: a review. Wetlands Ecology and Management, 16, 255-276.

Devillers, J. (2002). Acute toxicity of pesticides to honey bees. Honey bees: estimating the environmental impact of chemicals.London: Taylor and Francis, , 56-66.

Dukes, J., Zhong, H., Greer, M., Hester, P., Hogan, D. \& Barber, J.A. (2004). A comparison of two ultra-low-volume spray nozzle systems by using a multiple swath scenario for the aerial application of fenthion against adult mosquitoes. Journal of the American Mosquito Control Association, 20, 36-44.

Dunn, R.R., Harris, N.C., Colwell, R.K., Koh, L.P. \& Sodhi, N.S. (2009). The sixth mass coextinction: are most endangered species parasites and mutualists? Proceedings of the Royal Society of London B: Biological Sciences, 276, 3037-3045.

Eliazar, P.J. \& Emmel, T.C. (1991). Adverse impacts to non-target insects. Mosquito control pesticides: ecological impacts and management alternatives. Conference Proceedings. Scientific Publishers, Inc. Gainesville, Florida, 17-91 
Fischer, D., Alix, A., Coulson, M., Delorme, P., Moriarty, T. et al. (2014). Problem Formulation for an Assessment of Risk to Honey Bees from Applications of Plant Protection Products to Agricultural Crops.

Fischer, D. \& Moriarty, T. (2014). Pesticide risk assessment for pollinators.WileyBlackwell, 10-248.

Gann, G.D., Bradley, K., Woodmansee, S.W. \& Duquesnel, J.A. (2007). Floristic Inventory of the Florida Keys Database Online.

Haile, D.G., Mount, G.A. \& Pierce, N.W. (1982). Effect of droplet size of malathion aerosols on kill of caged adult mosquitoes. J.Am.Mosq.Control Assoc., , 576-582.

Hennessey, M.K. \& Habeck, D.H. (1991). Effects of mosquito adulticiding on populations of non-target, terrestrial arthropods in the Florida Keys. University of Florida.

Hennessey, M.K., Nigg, H.N. \& Habeck, D.H. (1992). Mosquito(Diptera: Culicidae) adulticide drift into wildlife refuges of the Florida Keys. Environmental Entomology, 21, 714-721.

Hoang, T.C., Pryor, R.L., Rand, G.M. \& Frakes, R.A. (2011). Use of butterflies as nontarget insect test species and the acute toxicity and hazard of mosquito control insecticides. Environmental Toxicology and Chemistry, 30, 997-1005.

Hodges, S.R. \& Bradley, K.A. (2006). Argythamnia blodgettii, Chamaecrista lineata var. keyensis, Indigofera mucronata var. keyensis, Linum arenicola, and Sideroxylon reclinatum subsp. austrofloridense.

Johansen, C.A. (1977). Pesticides and Pollinators. Annual Review of Entomology, 22, 177-192.

Johansen, C.A. (1972). Toxicity of Field-Weathered Insecticide Residues to Four Kinds of Bees. Environmental Entomology, 1, 393-394.

Johnson, S.D. \& Steiner, K.E. (2000). Generalization versus specialization in plant pollination systems. Trends in Ecology \& Evolution, 15, 140-143.

Kearns, C.A., Inouye, D.W. \& Waser, N.M. (1998). Endangered mutualisms: the conservation of plant-pollinator interactions. Annual Review of Ecology and Systematics, , 83-112.

Kearns, C.A. \& Inouye, D.W. (1993). Techniques for pollination biologists. University Press of Colorado, Niwot, Colo. 
Kearns, C.A. \& Inouye, D.W. (1994). Fly Pollination of Linum lewisii (Linaceae). American Journal of Botany, 81, 1091-1095.

Kevan, P.G. (1975). Forest application of the insecticide Fenitrothion and its effect on wild bee pollinators (Hymenoptera: Apoidea) of lowbush blueberries (Vaccinium spp.) in Southern New Brunswick, Canada. Biological Conservation, 7, 301-309.

Kevan, P.G., Greco, C.F. \& Belaoussoff, S. (1997). Log-normality of biodiversity and abundance in diagnosis and measuring of ecosystemic health: pesticide stress on pollinators on blueberry heaths. Journal of Applied Ecology, 1122-1136.

Kevan, P. \& Plowright, R. (1989). Fenitrothion and insect pollinators. Environmental Effects of Fenitrothion Use in Forestry: Impacts on Insect Pollinators, Songbirds, and Aquatic Organisms, , 13-42.

Kevan, P. \& Plowright, R. (1995). Impact of pesticides on forest pollination. Forest insect pests in Canada.Natural Resources Canada, Canadian Forest Service, Science and Sustainable Development Directorate, Ottawa, Ontario, Canada, , 607618.

Kevan, P.G., Clark, E.A. \& Thomas, V.G. (1990). Insect pollinators and sustainable agriculture. American Journal of Alternative Agriculture, 5, 13-22.

Koptur, S. (2006). The conservation of specialized and generalized pollination systems in subtropical ecosystems: a case study. Plant-pollinator interactions: from specialization to generalization.University of Chicago Press, Chicago, , 341-361.

Liu, H. \& Koptur, S. (2003). Breeding system and pollination of a narrowly endemic herb of the Lower Florida Keys: impacts of the urban-wildland interface. American Journal of Botany, 90, 1180-1187.

Liu, H. \& Pemberton, R.W. (2009). Solitary invasive orchid bee outperforms cooccurring native bees to promote fruit set of an invasive Solanum. Oecologia, 159, 515-525.

Longley, M. \& Sotherton, N.W. (1997). Factors determining the effects of pesticides upon butterflies inhabiting arable farmland. Agriculture, Ecosystems \& Environment, 61, 1-12.

Marcot, B.G. \& Molina, R. (2007). Special considerations for the science, conservation, and management of rare or little-known species. About Island Press, , 93.

Mount, G.A., Biery, T.L. \& Haile, D.G. (1996). A review of ultralow-volume aerial sprays of insecticide for mosquito control. Journal of the American Mosquito Control Association, 12, 601-618. 
Mulla, M., Darwazeh, H. \& Ede, L. (1982). Evaluation of new pyrethroids against immature mosquitoes and their effects on nontarget organisms. MOSQ.NEWS., 42, 583-589.

Niemi, G.J., Hershey, A.E., Shannon, L., Hanowski, J.M., Lima, A., Axler, R.P. et al. (1999). Ecological effects of mosquito control on zooplankton, insects, and birds. Environmental Toxicology and Chemistry, 18, 549-559.

Patterson, G. (2004). The Mosquito Wars: A History of Mosquito Control in Florida (Florida History and Culture), 1st edn. University Press of Florida.

Pierce, R.H., Henry, M.S., Blum, T.C. \& Mueller, E.M. (2005). Aerial and tidal transport of mosquito control pesticides into the Florida Keys National Marine Sanctuary. Revista de biología tropical, 53, 117.

Potts, S.G., Biesmeijer, J.C., Kremen, C., Neumann, P., Schweiger, O. \& Kunin, W.E. (2010). Global pollinator declines: trends, impacts and drivers. Trends in ecology \& evolution, 25, 345-353.

Proctor, M., Yeo, P. \& Lack, A. (1996). The natural history of pollination. Timber Press, Portland, Or.

Relyea, R.A. \& Diecks, N. (2008). AN UNFORESEEN CHAIN OF EVENTS: LETHAL EFFECTS OF PESTICIDES ON FROGS AT SUBLETHAL CONCENTRATIONS. Ecological Applications, 18, 1728-1742.

Ross, M.S., O'Brien, J.J. \& Flynn, L.J. (1992). Ecological site classification of Florida Keys terrestrial habitats. Biotropica, , 488-502.

Ross, M.S. \& Ruiz, P. (1996). A study of the distribution of several South Florida endemic plants in the Florida Keys. Unpublished report to the US Fish and Wildlife Service.Southeast Environmental Research Program, Florida International University, Miami, .

Salvato, M. (2001). Influence of mosquito control chemicals on butterflies (Nymphalidae, Lycaenidae, Hesperiidae) of the lower Florida Keys. JOURNAL-LEPIDOPTERISTS SOCIETY, 55, 8-14.

Schleier, J.J., Peterson, R.K.D., Irvine, K.M., Marshall, L.M., Weaver, D.K. \& Preftakes, C.J. (2012). Environmental fate model for ultra-low-volume insecticide applications used for adult mosquito management. STOTEN Science of the Total Environment, 438, 72-79.

Schleier, J.J. \& Peterson, R.K.D. (2014). The authors' reply: Environmental Toxicology and Chemistry, 33, 973-974. 
Shaw, J.L. \& Kennedy, J.H. (1996). The use of aquatic field mesocosm studies in risk assessment. Environmental Toxicology and Chemistry, 15, 605-607.

Skov, C. \& Wiley, J. (2005). ESTABLISHMENT OF THE NEOTROPICAL ORCHID BEE EUGLOSSA VIRIDISSIMA (HYMENOPTERA: APIDAE) IN FLORIDA. Florida Entomologist, 88, 225-227.

Spira, T.P. (2001). Plant-pollinator interactions: a threatened mutualism with implications for the ecology and management of rare plants. Natural Areas Journal, 21, 78-88.

Stewart-Oaten, A., Bence, J.R. \& Osenberg, C.W. (1992). Assessing Effects of Unreplicated Perturbations: No Simple Solutions. Ecology, 73, 1396-1404.

Tan, K. (1981a). Antifeeding effect of cypermethrin and permethrin at sub-lethal levels against Pieris brassicae larvae. Pesticide Science, 12, 619-626.

Tan, K. (1981b). Antifeeding effect of cypermethrin and permethrin at sub-lethal levels against Pieris brassicae larvae. PS Pesticide Science, 12, 619-626.

Tepedino, V.J. (2000). The reproductive biology of rare rangeland plants and their vulnerability to insecticides. Technical Bulletin, 1809.

Tepedino, V.J., Sipes, S., Barnes, J. \& Hickerson, L. (1996). The need for" extended care" in conservation: examples from studies of rare plants in the western United States. Acta Horticulturae, , 245-248.

Tepedino, V.J. (1979). THE IMPORTANCE OF BEES AND OTHER INSECT POLLINATORS IN MAINTAINING FLORAL SPECIES COMPOSITION. Great Basin Naturalist Memoirs, , 139-150.

Tietze, N.S., Shaffer, K.R. \& Hester, P.G. (1996). Half-life of naled under three test scenarios. Journal of the American Mosquito Control Association, 12, 251-254.

Tilman, D. (1994). Habitat destruction and the extinction debt. Nature (London), 371, 65; $65-66 ; 66$.

Tomlin, C. (2000). The pesticide manual : a world compendium. British Crop Protection Council, Farnham.

URS Corporation (2004). Naled Risk Assessment for the Endangered and Threatened Species of the Lower Keys. US Fish \& Wildlife Service South Florida Ecological Services.

USEPA (1997). EFED's Reregistration Chapter for Naled. Environmental Fate and Effects Division (7507C). 
USEPA (2002). Interim Reregistration Eligibility Decision for Naled. Environmental Protection and Toxic Substances (7508C).

USEPA (2006). Reregistration eligibility decision (RED) for permethrin. U.S. Environmental Protection Agency, Prevention, Pesticides and Toxic Substances, Washington, DC.

USFWS (2010a). Endangered and Threatened Wildlife and Plants; Post-Delisting Monitoring Plan for Bald Eagle (Haliaeetus leucocephalus). Federal Register, 75, 31811.

USFWS (2010b). Key Tree Cactus 5-year Review. United States Fish \& Wildlife Service, Southeast Region, South Florida Ecological Services.

USFWS (2014). Endangered and Threatened Wildlife and Plants; Designation of Critical Habitat for Florida Leafwing and Bartram's Scrub-Hairstreak Butterflies. Federal Register, 79, 47180-47220.

USFWS (2015). Endangered Status for Chamaecrista lineata var. keyensis, Chamaesyce deltoidea ssp. serpyllum, Linum arenicola, and Argythamnia blodgettii, Four Plants from South Florida. Federal Register, 80, 58536.

Vaughan, M., Vaissiere, B., Maynard, G., Kasina, M., Nocelli, R. et al. (2014). 3 Overview of Non-Apis Bees. John Wiley \& Sons.

Wisk, J.D., Pistorius, J., Beevers, M., Bireley, R., Browning, Z., Chauzat, M.P. et al. (2014). Assessing exposure of pesticides to bees. Pesticide Risk Assessment for Pollinators (ed Fisher, D. and Moriarty, T), pp. 45-74.

Xiao, Y., Li, X., Cao, Y. \& Dong, M. (2016). The diverse effects of habitat fragmentation on plantâ€"pollinator interactions. Plant Ecology, 217, 857-868.

Zhong, H., Hribar, L.J., Daniels, J.C., Feken, M.A., Brock, C. \& Trager, M.D. (2010). Aerial ultra-low-volume application of naled: impact on nontarget imperiled butterfly larvae (Cyclargus thomasi bethunebakeri) and efficacy against adult mosquitoes (Aedes taeniorhynchus). Environmental Entomology, 39, 1961-1972. 


\section{Appendix}

Focal species: Pentalinon luteum

\begin{tabular}{|c|c|c|c|c|c|c|c|c|c|c|}
\hline \multirow[b]{2}{*}{ Site } & \multicolumn{3}{|c|}{ Round 1} & \multicolumn{3}{|c|}{ Round 2} & \multicolumn{3}{|c|}{ Round 3} & \\
\hline & $\begin{array}{l}\text { Truck } \\
\text { spray }\end{array}$ & $\begin{array}{l}\text { Aerial } \\
\text { Spray }\end{array}$ & Total & $\begin{array}{l}\text { Truck } \\
\text { Spray }\end{array}$ & $\begin{array}{l}\text { Aerial } \\
\text { Spray }\end{array}$ & Total & $\begin{array}{l}\text { Truck } \\
\text { Spray }\end{array}$ & $\begin{array}{l}\text { Aerial } \\
\text { Spray }\end{array}$ & Total & $\begin{array}{l}\text { Total } \\
2015^{*}\end{array}$ \\
\hline 3 & 0 & 0 & 0 & 0 & 0 & 0 & 0 & 0 & 0 & 0 \\
\hline 4 & 0 & 0 & 0 & 0 & 0 & 0 & 0 & 0 & 0 & 0 \\
\hline 6 & 0 & 0 & 0 & 0 & 0 & 0 & 0 & 0 & 0 & 0 \\
\hline 10 & 11 & 4 & 15 & 12 & 4 & 16 & 12 & 5 & 17 & 29 \\
\hline 11 & 0 & 0 & 0 & 1 & 0 & 1 & N/A & N/A & N/A & 1 \\
\hline
\end{tabular}

Focal species: Linum arenicola

\begin{tabular}{|c|c|c|c|c|c|c|c|c|c|c|}
\hline \multirow[b]{2}{*}{ Site } & \multicolumn{3}{|c|}{ Round 1} & \multicolumn{2}{|c|}{ Round 2} & \multicolumn{4}{|c|}{ Round 3} & \multirow{2}{*}{$\begin{array}{l}\text { Site } \\
\text { Total } \\
2015^{*}\end{array}$} \\
\hline & $\begin{array}{l}\text { Truck } \\
\text { spray }\end{array}$ & $\begin{array}{l}\text { Aerial } \\
\text { Spray }\end{array}$ & Total & $\begin{array}{l}\text { Truck } \\
\text { Spray }\end{array}$ & $\begin{array}{l}\text { Aerial } \\
\text { Spray }\end{array}$ & Total & $\begin{array}{l}\text { Truck } \\
\text { Spray }\end{array}$ & $\begin{array}{l}\text { Aerial } \\
\text { Spray }\end{array}$ & Total & \\
\hline 1 & 0 & 0 & 0 & 0 & 0 & 0 & 0 & 0 & 0 & 0 \\
\hline 2 & 0 & 0 & 0 & 0 & 0 & 0 & 0 & 0 & 0 & 0 \\
\hline 6 & 0 & 0 & 0 & 0 & 0 & 0 & 0 & 0 & 0 & 0 \\
\hline 10 & 11 & 4 & 15 & 12 & 4 & 16 & 12 & 5 & 17 & 29 \\
\hline
\end{tabular}

Focal species: Chamaecrista lineata var. keyensis

\begin{tabular}{|c|c|c|c|c|c|c|c|c|c|c|}
\hline \multirow[b]{2}{*}{ Site } & \multicolumn{3}{|c|}{ Round 1} & \multicolumn{2}{|c|}{ Round 2} & \multicolumn{4}{|c|}{ Round 3} & \multirow[b]{2}{*}{$\begin{array}{c}\text { Site } \\
\text { Total } \\
2015^{*}\end{array}$} \\
\hline & $\begin{array}{l}\text { Truck } \\
\text { spray }\end{array}$ & $\begin{array}{l}\text { Aerial } \\
\text { Spray }\end{array}$ & Total & $\begin{array}{l}\text { Truck } \\
\text { Spray }\end{array}$ & $\begin{array}{l}\text { Aerial } \\
\text { Spray }\end{array}$ & Total & $\begin{array}{l}\text { Truck } \\
\text { Spray }\end{array}$ & $\begin{array}{l}\text { Aerial } \\
\text { Spray }\end{array}$ & Total & \\
\hline 1 & 0 & 0 & 0 & 0 & 0 & 0 & 0 & 0 & 0 & 0 \\
\hline 3 & 0 & 0 & 0 & 0 & 0 & 0 & 0 & 0 & 0 & 0 \\
\hline 5 & 1 & 0 & 1 & 2 & 0 & 2 & 3 & 0 & 3 & 8 \\
\hline 8 & 0 & 0 & 0 & 0 & 0 & 0 & 0 & 0 & 0 & 0 \\
\hline 9 & 0 & 0 & 0 & 0 & 0 & 0 & 0 & 0 & 0 & 0 \\
\hline
\end{tabular}

A1. The number of insecticide spray missions (truck, aerial, and total) that occurred in 2015 at each site for each focal species before a sampling round took place. The bold number in each round is the application type (truck or aerial) that occurred immediately before that sampling round. * Site Total for 2015 are the number of insecticide mission for all of the 2015 mosquito spray season: 5/5/2015 - 10/7/2015. Sampling efforts occurred in the middle of the mosquito spray season when peak flowering coincided with peak spray season. 